\title{
The Growth of 3T3 Fibroblasts on PHB, PLA and PHB/PLA Blend Films at Different Stages of Their Biodegradation In Vitro
}

\author{
Vsevolod A. Zhuikov ${ }^{1}$ (D), Elizaveta A. Akoulina ${ }^{2}$ D, Dariana V. Chesnokova ${ }^{2}$, , You Wenhao $^{3}$, \\ Tatiana K. Makhina ${ }^{1}$, Irina V. Demyanova ${ }^{3}$, Yuliya V. Zhuikova ${ }^{1}$, Vera V. Voinova ${ }^{2}$, Nikita V. Belishev ${ }^{2}$, \\ Roman A. Surmenev ${ }^{4}$ (D), Maria A. Surmeneva ${ }^{4}$, Garina A. Bonartseva ${ }^{1}$, Konstantin V. Shaitan ${ }^{2}$ \\ and Anton P. Bonartsev ${ }^{2, *}$
}

check for updates

Citation: Zhuikov, V.A.;

Akoulina, E.A.; Chesnokova, D.V.; Wenhao, Y.; Makhina, T.K.; Demyanova, I.V.; Zhuikova, Y.V.; Voinova, V.V.; Belishev, N.V.; Surmenev, R.A.; et al. The Growth of 3T3 Fibroblasts on PHB, PLA and PHB/PLA Blend Films at Different Stages of Their Biodegradation In Vitro. Polymers 2021, 13, 108. https://doi.org/10.3390/ polym13010108

Received: 30 November 2020 Accepted: 23 December 2020 Published: 29 December 2020

Publisher's Note: MDPI stays neutral with regard to jurisdictional clai$\mathrm{ms}$ in published maps and institutional affiliations.

Copyright: (C) 2020 by the authors. Licensee MDPI, Basel, Switzerland. This article is an open access article distributed under the terms and conditions of the Creative Commons Attribution (CC BY) license (https:// creativecommons.org/licenses/by/ $4.0 /)$
1 Research Center of Biotechnology of the Russian Academy of Sciences, Leninsky Ave, 33, Bld. 2, 119071 Moscow, Russia; vsevolod1905@yandex.ru (V.A.Z.); tat.makhina@gmail.com (T.K.M.) zhuikova.uv@gmail.com (Y.V.Z.); bonar@inbi.ras.ru (G.A.B.)

2 Faculty of Biology, M.V. Lomonosov Moscow State University, Leninskie Gory 1-12, 119234 Moscow, Russia; akoulinaliza@gmail.com (E.A.A.); daryana8@yandex.ru (D.V.C.); veravoinova@mail.ru (V.V.V.); nbelishev@gmail.com (N.V.B.); shaytan49@yandex.ru (K.V.S.)

3 Biological Faculty, Shenzhen MSU-BIT University, No.299, Ruyi Road, Longgang District, Shenzhen 518172, China; tess120@foxmail.com (Y.W.); irinydem@yandex.com (I.V.D.)

4 National Research Tomsk Polytechnic University, Lenin Ave, 30, 634050 Tomsk, Russia; surmenev@tpu.ru (R.A.S.); surmenevamaria@mail.ru (M.A.S.)

* Correspondence: ant_bonar@mail.ru; Tel.: +7-4959306306

\begin{abstract}
Over the past century there was a significant development and extensive application of biodegradable and biocompatible polymers for their biomedical applications. This research investigates the dynamic change in properties of biodegradable polymers: poly(3-hydroxybutyrate (PHB), poly-L-lactide (PLA), and their 50:50 blend (PHB/PLA)) during their hydrolytic non-enzymatic (in phosphate buffered saline (PBS), at $\mathrm{pH}=7.4,37^{\circ} \mathrm{C}$ ) and enzymatic degradation (in PBS supplemented with $0.25 \mathrm{mg} / \mathrm{mL}$ pancreatic lipase). 3T3 fibroblast proliferation on the polymer films experiencing different degradation durations was also studied. Enzymatic degradation significantly accelerated the degradation rate of polymers compared to non-enzymatic hydrolytic degradation, whereas the seeding of 3T3 cells on the polymer films accelerated only the PLA molecular weight loss. Surprisingly, the immiscible nature of PHB/PLA blend (showed by differential scanning calorimetry) led to a slower and more uniform enzymatic degradation in comparison with pure polymers, PHB and PLA, which displayed a two-stage degradation process. PHB/PLA blend also displayed relatively stable cell viability on films upon exposure to degradation of different durations, which was associated with the uneven distribution of cells on polymer films. Thus, the obtained data are of great benefit for designing biodegradable scaffolds based on polymer blends for tissue engineering.
\end{abstract}

Keywords: poly(3-hydroxybutyrate); poly-L-lactide; polymer blend; biodegradation; hydrolysis; pancreatic lipase; 3 T3 fibroblasts; nanoparticles

\section{Introduction}

Poly(3-hydroxybutyrate) (PHB) and polylactic acid (PLA) are two most widely used biodegradable and renewable polyesters, which bear the potential to replace petroleumderived polymers [1]. PHB and PLA have also gained vast attention in the investigation of biomaterials-based products [1-3].

Poly(3-hydroxybutyrate) (PHB) is a reserve carbon source found in many types of bacteria with chemical structure demonstrated in Figure 1 [4,5]. PHB can be synthesized in various natural environments and it is produced biotechnologically by a series producing strains, such as Cupriavidus eutrophus [6] or Azotobacter chroococcum [7]. PHB has the 
ability to degrade into the monomer, 3-hydroxybutyric acid, which is nontoxic and can be removed through metabolism $[8,9]$. PLA is a polyester produced by chemical synthesis from lactic acid. Lactic acid, the monomer of PLA, is produced from sugar or starch using bacterial fermentation or petrochemical methods. PLA can be also hydrolyzed to its monomer $\alpha$-hydroxy acid within living organisms. This monomer is then further metabolized through tricarboxylic acid cycle [10]. Moreover, PLA degradation products are non-toxic and environmentally friendly, making it a first choice for biomedical and industrial applications, such as biomedical implants and food packaging [11-13]. However, the PLA degradation products, which are formed during rapid hydrolysis have no time to be taken up by the organism, which causes a drastic $\mathrm{pH}$ decrease in proximity to the implant. Chronic tissue irritation caused by reduced $\mathrm{pH}$ is considered a serious problem associated with the use of PLA-based polymer implants [14].
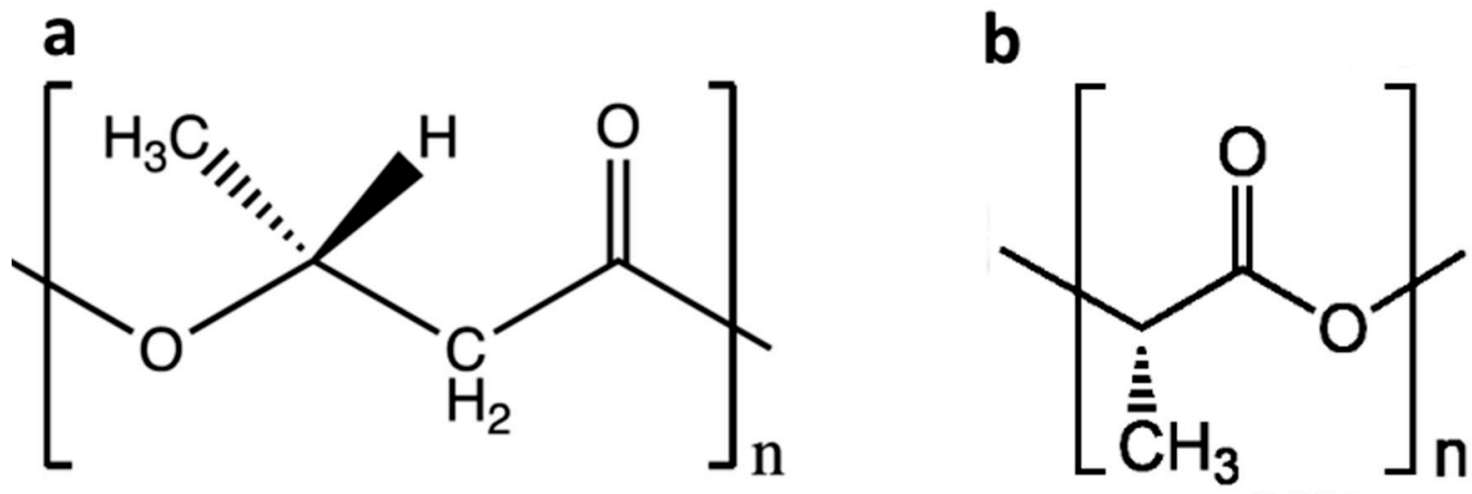

Figure 1. The chemical structure of PHB (a) and PLA (b).

Unlike petro-derived polymers, PHB and PLA exhibit favorable features of biocompatibility, biodegradability, and eco-friendliness, which are very important aspects of biomaterial-based product development. Those features made PLA- and PHB-based materials being exclusively used in many fields ranging from medicine to industrial manufacturing [15-21]. Commercially available PLA films and packages are becoming indispensable components for daily life products, while biomedical field has witnessed the great potential of PLA-derived polymers as biocompatible sutures and medical implants. PHB plays a crucial role in designing strategies related to regenerative medicine and tissue engineering due to its superior and desirable characteristics. PHB-based biomaterials have demonstrated their validity for production of conventional medical implantation devices, controlled drug delivery systems, and tissues engineered constructs, including repair patches, scaffolds, adhesion barriers, drug delivery platforms and sutures [22-25].

A large number of research has been dedicated to the investigation of these biopolymers' characteristics, including biodegradability, biocompatibility and mechanical properties, which deepen knowledge of PHB and PLA-based materials [26-29]. The ability to promote the use of PHAs will be facilitated by the improved understanding of their biodegradability mechanism [30,31]. Despite the presence of a large amount of research that investigates the applications and modifications of PHA, there was a lack of studies regarding the PHA degradation, e.g., surface interaction with cells and dynamic changes of the properties of PHAs. In this research polymer films from PHB and PLA were fabricated for degradation study and cell experiments.

Currently there is a lack of research investigating the impact of culturing cells on polymer films and scaffolds on polymer degradation [32]. The role of degradation products in cell growth on polymer scaffolds is also poorly understood [33].

The goal of this project is to study dynamic changes of polymer's properties, and the interaction between biopolymers and cells during the degradation course. 


\section{Materials and Methods}

\subsection{Materials}

Bacterial PHB powder was purchased from Biomer (Schwalbach, Germany); PLA and Lipase (isolated from porcine pancreas) were obtained from Merck (former Sigma-Aldrich, Darmstadt, Germany), and bovine serum albumin (BSA) was purchased from Aladdin Industrial Corporation (Shanghai, China).

\subsection{Fabrication of Polymer Films}

Polymer films were prepared by solution-casting method. Chloroform was used as a solvent for both polymers. A solution of chloroform with a polymer (1.2\%) was casted into Petri dishes with a diameter of $9 \mathrm{~cm}$, and Petri dishes were left in the fume cupboard for $24 \mathrm{~h}$ until all chloroform evaporated. Finally, films were removed from Petri dishes and cut into small disks (diameter: $1.5 \pm 0.2 \mathrm{~cm}$, thickness: $40 \pm 5 \mu \mathrm{m}$, weight: $9 \pm 3 \mathrm{mg}$ ). A polymer mixture of PLA and PHB (50:50) was made by mixing solutions of PHB and PLA with thorough mixing.

\subsection{Enzymatic and Non-Enzymatic Hydrolytic Degradation}

Non-enzymatic degradation was conducted in phosphate buffer saline (PBS) Merck (former Sigma-Aldrich, Darmstadt, Germany) at $\mathrm{pH}$ of 7.4. For enzymatic degradation, lipase was added to PBS with a concentration of $0.25 \mathrm{mg} / \mathrm{mL}$. All solutions were stored in a shaker-incubator $\left(37^{\circ} \mathrm{C}, 150 \mathrm{rpm}\right)$. To maintain the buffer quality, free PBS buffer and lipase-containing PBS buffer were changed every 3 days. Films were examined at 4 different degradation points ( 1 week, 2 weeks, 4 weeks and 6 weeks). To prevent bacterial contribution to the degradation of polymers, sodium azide $(2 \mathrm{~g} / \mathrm{L})$ was added to the buffer solution.

\subsection{T3 Cell Seeding Experiments}

Murine NIH 3T3 fibroblasts (Biolot, Russia) were used to study the interaction between polymer films and cells at different degradation stages. Cell growth medium was made according to the protocol: Dulbecco's modified eagle medium (DMEM, PanEco, Moscow, Russia) supplemented with 10\% fetal bovine serum (FCS, Biological Industries, Beit-Haemek, Israel), $100 \mathrm{U} / \mathrm{mL}$ penicillin (PanEco, Moscow, Russia). The experiment consisted of two parts. For the first part, the experiment was carried out on cell culture plate (24 wells with a diameter of $1.5 \mathrm{~cm}$ ). Fresh-made films were immersed in ethanol for sterilization (for at least $1 \mathrm{~h}$ ), followed by washing with sterile PBS. Then, films were flattened and fixed to the bottom of wells. For cell seeding, we added $200 \mu \mathrm{L}$ of cell suspension (about $2 \times 10^{5}$ cells) and $800 \mu \mathrm{L}$ of cell growth medium into each well. Finally, the cell culture plate was stored in the $\mathrm{CO}_{2}$ incubator (Sony, Minato, Tokyo, Japan) at $37{ }^{\circ} \mathrm{C}$. Degradation of films and the growth of $3 \mathrm{~T} 3$ cells were observed at 2 different time points: 1 week, 2 weeks. The second cell experiment was performed on a 96-well plate, and the samples included fresh-made films, films after 2-week's and 6-week-'s degradation. After sterilization, each film was cut into 3 identical pieces, followed by fixation into 96-well plate. For each well, $100 \mu \mathrm{L}$ of $3 \mathrm{~T} 3$ cell solution $\left(2 \times 10^{5}\right.$ cells $)$ together with $200 \mu \mathrm{L}$ cell growth medium was added for cell seeding. The plate was incubated at $37^{\circ} \mathrm{C}$ with $\mathrm{CO}_{2}$ rate $5.0 \%$, and the cell viability test was conducted at 3 different time points $(1 \mathrm{~d}, 3 \mathrm{~d}$ and $5 \mathrm{~d})$. The approvals for all experimental procedures and ethical guidelines were issued by the ISO 10993-1:2009.

\subsection{Weight Loss Analysis of Polymer Films}

Weight loss measurement were carried out at 4 different degradation points (1 week, 2 weeks, 4 weeks and 6 weeks). The changes in the weight of the films during the degradation were determined gravimetrically on the AL-64 scales (Max $=60 \mathrm{~g}, \mathrm{~d}=0.1 \mathrm{mg}$, Acculab (Sartorius Group), Göttingen, Germany). At each time point, films were taken out of the degradation buffer and washed with distilled water, followed by immersing in $0.1 \%$ SDS 
solution for $24 \mathrm{~h}$. After that, films were washed with distilled water and then dried out. Finally, the weight of each film was measured using microbalance. The weight loss was calculated using the following equation:

$$
\text { weight loss }(\%)=\frac{\mathrm{W}_{0}-\mathrm{W}_{d}}{\mathrm{~W}_{0}} \times 100 \%
$$

where $W_{0}$ is the initial sample weight and $W_{d}$ represents measured sample weight after degradation.

\subsection{Particle Distribution Analysis of Film Degradation Products}

Samples of PHB, PLA, and PHB-PLA polymer films of the same weight were washed twice and incubated in milli-Q water at $37^{\circ} \mathrm{C}$ with constant stirring. After 7 and 14 days of incubation, the films were removed, and the remaining solutions were centrifuged twice for $5 \mathrm{~min}$ at 10,000 rpm. The resulting supernatants were analyzed for polymer degradation products by Dynamic light scattering using a Zetasizer Nano ZS (Malvern Panalytical, Malvern, UK). The distribution of nano- and microparticles size was recorded using Zetasizer Software in four independent replicates.

\subsection{Molecular Weight (Mw) Analysis}

Ubbelohde viscometer was used to measure the viscosity of PHB, PLA and PHB/PLA blend. Polymer film was dissolved in $7 \mathrm{~mL}$ chloroform, and the solution was transferred into viscometer. The experiment was carried out in water bath at $30^{\circ} \mathrm{C}$ (Supplementary, Figures S1 and S2). For each sample, the viscosity measurement was repeated 3 times. Molecular weights of PHB and PLA were calculated using Mark-Houwink-Kuhn-Sakurada (MHKS) equation [7]. The molecular weight of PHB/PLA blend was approximated using the known ratios of PHB and PLA and the rate of their decomposition (Supplemental Materials, Figures S1 and S2).

\subsection{Differential Scanning Calorimetry (DSC)}

Thermal properties of PHB, PLA and the blend were measured via differential scanning calorimetry using a DSC 204 F1 Phoenix (Netzsch, Selb, Germany) equipment. The samples were heated from 25 to $200{ }^{\circ} \mathrm{C}$ at a heating rate of $10{ }^{\circ} \mathrm{C} / \mathrm{min}$ in nitrogen environment. The onset and peak temperature of the change in heat capacity was designated as the (onset) and (peak). The accuracy of obtained values did not exceed $1{ }^{\circ} \mathrm{C}$ for the temperature measure and $2 \mathrm{~J} / \mathrm{g}$ for the melting enthalpy. The crystallinity of biopolymer component (Xc) was calculated by the following equation [34]:

$$
\begin{gathered}
\mathrm{Xc}_{\mathrm{c}}(\mathrm{PHB})=\Delta \mathrm{Hm} / \Delta \mathrm{H}^{0} \mathrm{~m}(\mathrm{PHB}) \\
\mathrm{Xc}_{\mathrm{c}}(\mathrm{PLA})=\Delta \mathrm{Hm} / \Delta \mathrm{H}^{0} \mathrm{~m}(\mathrm{PLA}) \\
\mathrm{Xc}_{\mathrm{c}}(\mathrm{PHB})=\frac{\Delta \mathrm{Hm}}{\Delta \mathrm{H}^{0} \mathrm{~m}(\mathrm{PHB})} \times \omega(\mathrm{PHB}) \\
\mathrm{X}_{\mathrm{c}}(\mathrm{PLA})=\frac{\Delta \mathrm{Hm}}{\Delta \mathrm{H}^{0} \mathrm{~m}(\mathrm{PLA})} \times \omega(\mathrm{PLA})
\end{gathered}
$$

where $\Delta H^{0} \mathrm{~m}$ (PHB) and $\Delta \mathrm{H}^{0} \mathrm{~m}$ (PLA)represent the theoretical values for the thermodynamic melting enthalpy of completely crystallized PHB $(146.6 \mathrm{~J} / \mathrm{g})$ and PLA (93.1 J/g), respectively. $\triangle \mathrm{Hm}$ is the melting enthalpy that was calculated from DSC curve. (PHB) and (PLA) are the weight fractions of PHB and PLA in the blend. All calculations were performed for the second heating cycle. Data was presented as the average of three measurements, $p$ values $<0.05$ were considered statistically significant. 


\subsection{Scanning Electron Microscopy}

To investigate the changes of surface structure and cell distribution, scanning electron microscopy (SEM) and fluorescence microscopy were used. For the SEM's sample preparation standard dehydration process was conducted using different concentrations of ethanol (30\%, 50\%, 70\% and 96\%). After that, Hexamethyldisilazane (HMDS) was used to replace ethanol during sample drying. Finally, the specimens were mounted on metal stubs; then stubs were coated with silver in a sputtering device for $15 \mathrm{~min}$ at $15 \mathrm{~mA}$ (IB-3, Giko, Fukuoka, Japan) and examined under a scanning electron microscope JSM-6380LA (Jeol, Akishima, Tokyo, Japan). For fluorescence microscope films were cut into small pieces, followed by their immersion in PBS buffer containing Calcein for $15 \mathrm{~min}$. After that, samples were removed from solution and washed by PBS. Finally, the samples were analyzed using fluorescence microscope (blue filter) ZEISS Axio Lab A1 (Zeiss, Oberkochen, Germany).

\subsection{Cell Proliferation Assay XTT Test}

In order to determine the viability of NIH 3T3 fibroblasts seeded on films XTT cell proliferation test was used. Films were removed from the medium and cut into identical pieces. The film fragments were then transferred into a 96-well plate. For each well $100 \mu \mathrm{L}$ of DMEM and $50 \mu \mathrm{L}$ of reaction solution of Cell Proliferation Kit XTT (Biological Industries, Israel: $2 \%$ activation solution plus $98 \%$ XTT reagent solution was added followed by the plate incubation for $2 \mathrm{~h}$ at $37^{\circ} \mathrm{C}$. Film fragments were taken out of the wells after 2-h incubation. After that, the measurement of the absorbance of the samples was carried out using Zenyth 3100 Microplate Multimode Detector (Anthos Labtec Instruments GmbH, Wals, Austria) at a wavelength of $450 \mathrm{~nm} ; 630 \mathrm{~nm}$ wavelength was used as a reference absorbance. Then the calibration plot "cell number-absorbance at $450 \mathrm{~nm}$ " was built using the known number of the same cells counted by light microscope with the micrometer scale [35].

\subsection{Statistical Analysis}

Each experiment was conducted from 2 to 3 times with 3 samples for each polymer material (PHB, PLA, PHB/PLA). The non-parametric Kruskal-Wallis test was employed for the statistical evaluation of data using the software package SPSS/PC+ Statistics ${ }^{\text {TM }} 12.1$ (SPSS: An IBM Company, Armonk, NY, USA). The obtained data were represented as mean $\pm \mathrm{SD}$ (standard error of the mean), and was considered significant for $p<0.05$.

\section{Results}

\subsection{Weight Loss of Biopolymer Films}

In the degradation experiment, the dynamic changes of the main physicochemical properties concerning three different biopolymers (PLA, PHB and blend 50/50) were measured. Weight loss occurred at every degradation point, though it varied in different polymer films, as shown in Figure 2. PLA and PHB/PLA with enzymatic degradation had a greater weight loss than in conditions of non-enzymatic hydrolytic degradation, whereas both degradation types caused the approximately same weight loss of PHB films. In both enzymatic and non-enzymatic degradations, weight loss increased with the increment of time with access to a relative plateau. Among three types of polymer films, PLA and PHB/PLA blend had greater weight loss values compared with PHB. Notably, PHB/PLA blend exhibited the highest weight loss (up to 35\%) after 6 weeks' enzymatic degradation though it had smaller values than PLA at other observation points. 


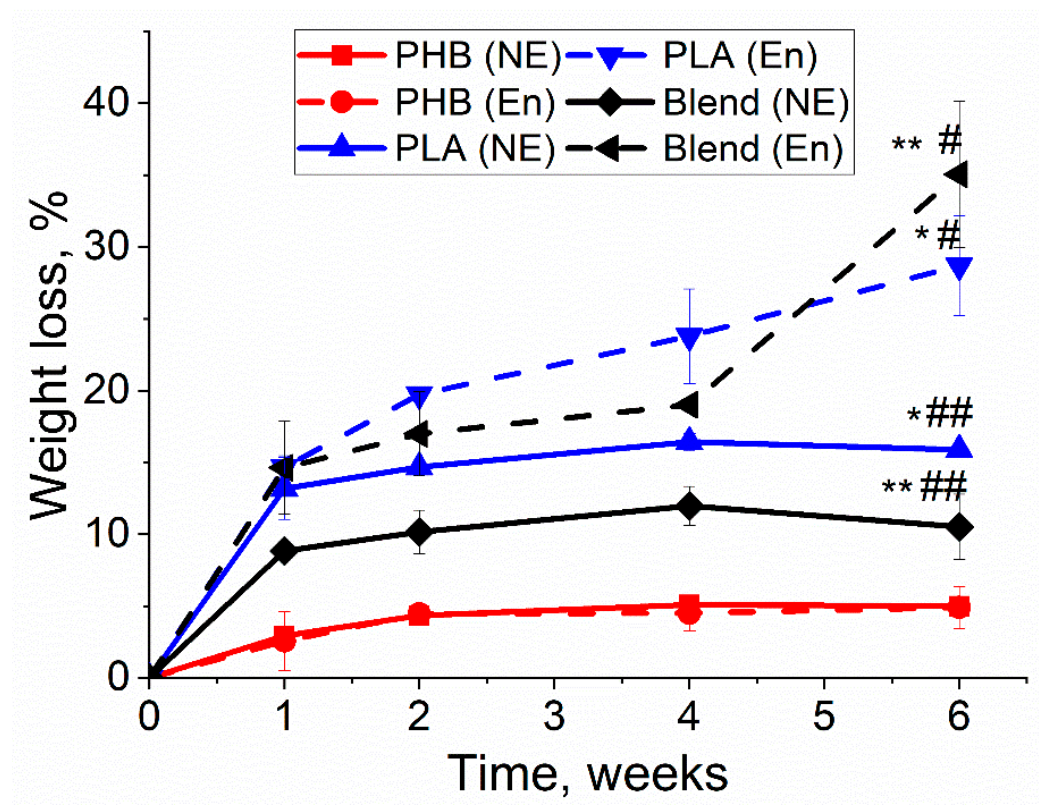

Figure 2. The weight loss of PHB, PLA and PHB/PLA films during enzymatic (En) and non-enzymatic (NE) degradation (NE-incubation in phosphate buffer saline without lipase, En-incubation in phosphate buffer saline with lipase). * PLA (E) vs. PLA (NE), $p<0.05$; ** Blend (E) vs. Blend (NE), $p<0.05$; \# PLA (E) \& Blend (E) vs. PHB (E), $p<0.05$; \#\# PLA (NE) \& Blend (NE) vs. PHB (NE), $p<0.05$.

During the first two weeks, the greatest weight loss of all samples was observed, regardless of the lipase presence in the solution. To determine the nature of these changes, the degradation products of polymer films in milli-Q water were examined using dynamic light scattering technique. According to the data from the first week measurements, the particles of polymer films degradation products were hard to detect in milli-Q water, due to their low concentration (especially for PLA) (Figure 3a-c). It should be noted that the low concentration of degradation products can reduce the accuracy of measuring their size.

However the PHB sample had a one relatively narrow peak at $205 \mathrm{~nm}$, PLA sample had two peaks, whereas the PHB/PLA blend sample had a wide peak with a relatively wide fraction of large particles, which is consistent with the data on the weight loss of polymers in the first week of their non-enzymatic degradation.

At the second week, there were clear peaks for particulate degradation products of PHB with the following maxima: 3, 10, 340 and $5500 \mathrm{~nm}$, PLA: 0.9, 300 and $5500 \mathrm{~nm}$ (the last-measured value limit), and for PHB/PLA blend films: 4.1, 340-530 and $5500 \mathrm{~nm}$ (the last-measured value limit) (Figure $4 \mathrm{a}-\mathrm{c}$ ).

\subsection{Molecular Weight Loss of Biopolymer Films}

Molecular weight is one of the key properties of biopolymers. Its decrease is a good indication of the ongoing degradation process. It can be observed that the molecular weight decreased for all three polymers during both enzymatic and non-enzymatic degradation (Figure 5). In comparison to non-enzymatic hydrolitic degradation, all three polymers had larger molecular weight loss with the involvement of lipase in enzymatic degradation. Moreover, PHB had the highest molecular weight loss (45\%) under enzymatic degradation, whereas PLA had smaller molecular weight loss (41\%) and the PHB/PLA blend demonstrated the smallest molecular weight loss (36\%). It can also be noticed that PHB had the highest initial molecular weight (253 kDa), while PLA and the blend had smaller initial molecular weight values. Despite that the viscosity of PHB had a drastic decrease during the first 3 weeks, no significant changes in the viscosity were observed in the last two weeks of degradation. The decrease in MM in PHB/PLA blend was more even. 


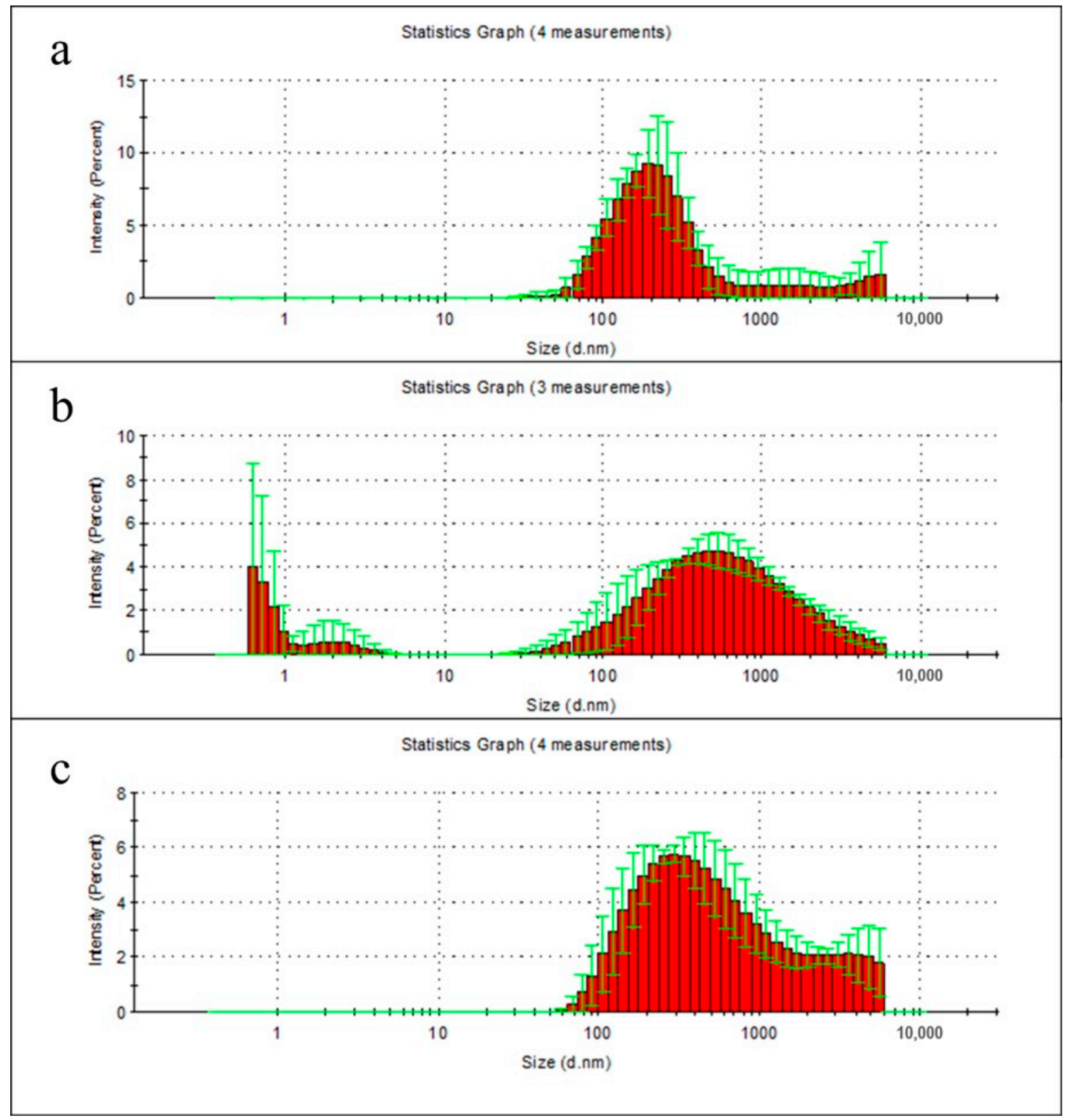

Figure 3. Size distribution of particulate degradation products of PHB (a), PLA (b), and PHB/PLA blend films (c) after 1 week incubation in milli-Q water. Data presented as mean \pm SD.

The first-order kinetic model on the observed exponential decrease of molecular weight in time (Figure 6, Table 1) was applied for polymer film degradation in PBS without enzyme and in lipase solution. These values indicated much higher degradation kinetics of the studied polymers than previously published PHB degradation in similar environment [36]. 


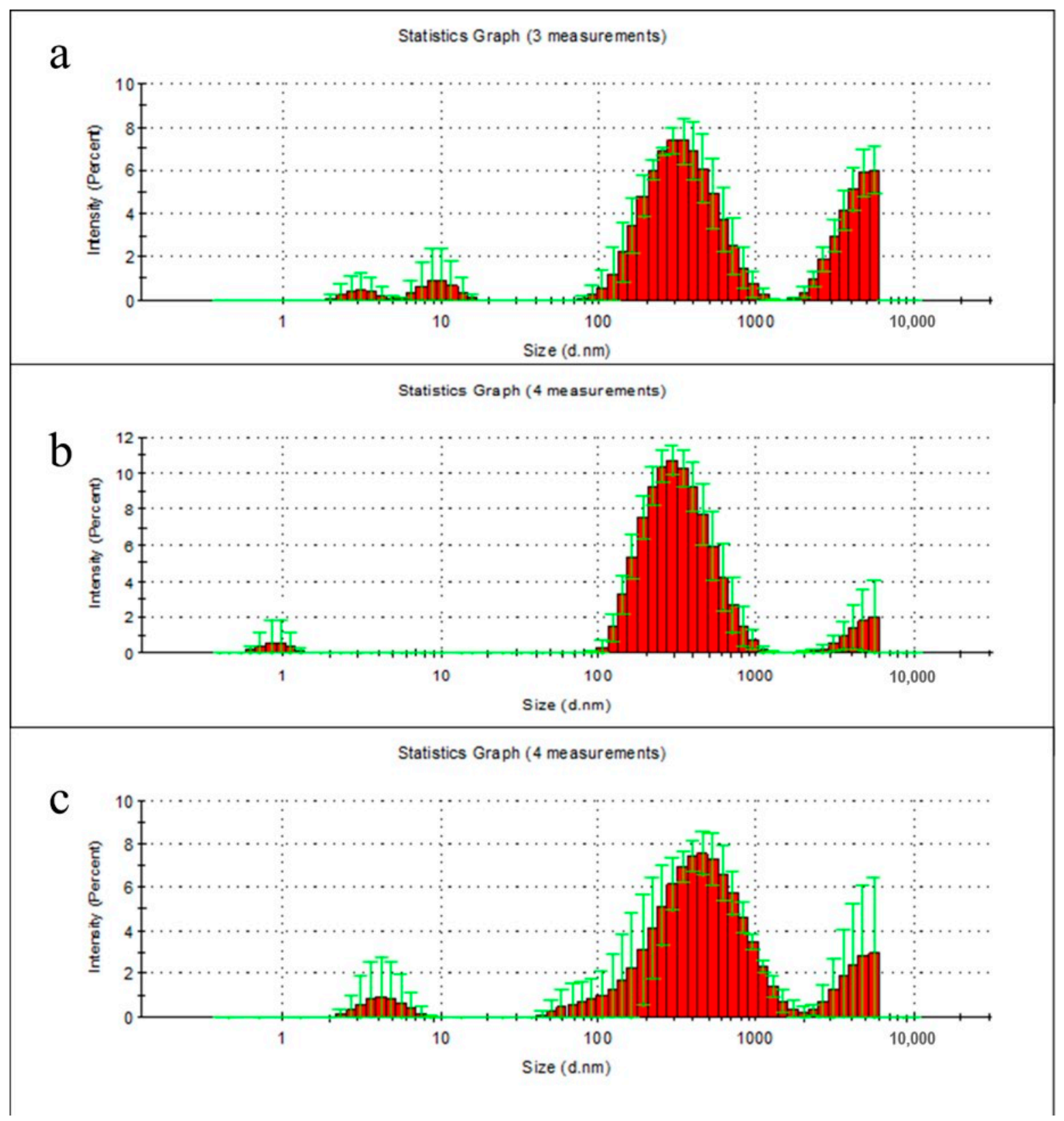

Figure 4. Size distribution of particulate degradation products of PHB (a), PLA (b), and PHB/PLA blend films (c) after 2 weeks incubation in milli-Q water. Data presented as mean \pm SD. 


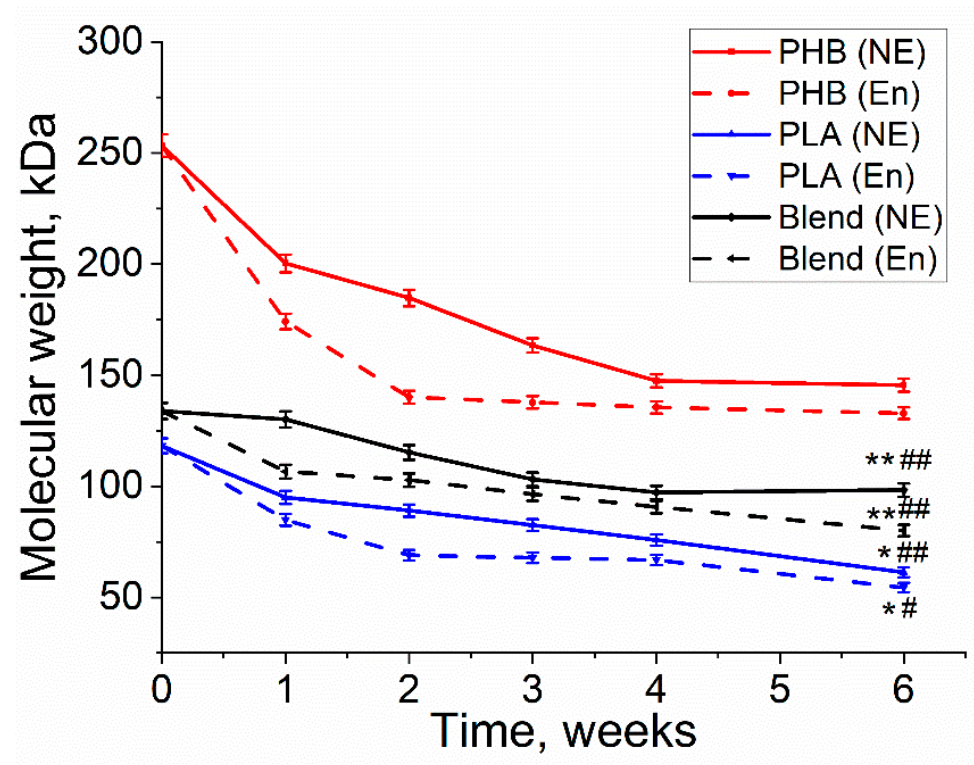

Figure 5. The loss of molecular weight of PHB, PLA, and PHB/PLA during enzymatic (En) and non-enzymatic (NE) degradation. * PLA (E) vs. PLA (NE), $p<0.05 ;{ }^{* *}$ Blend (E) vs. Blend (NE), $p<0.05$; \# PLA (E) \& Blend (E) vs. PHB (E), $p<0.05$; \#\# PLA (NE) \& Blend (NE) vs. PHB (NE), $p<0.05$.
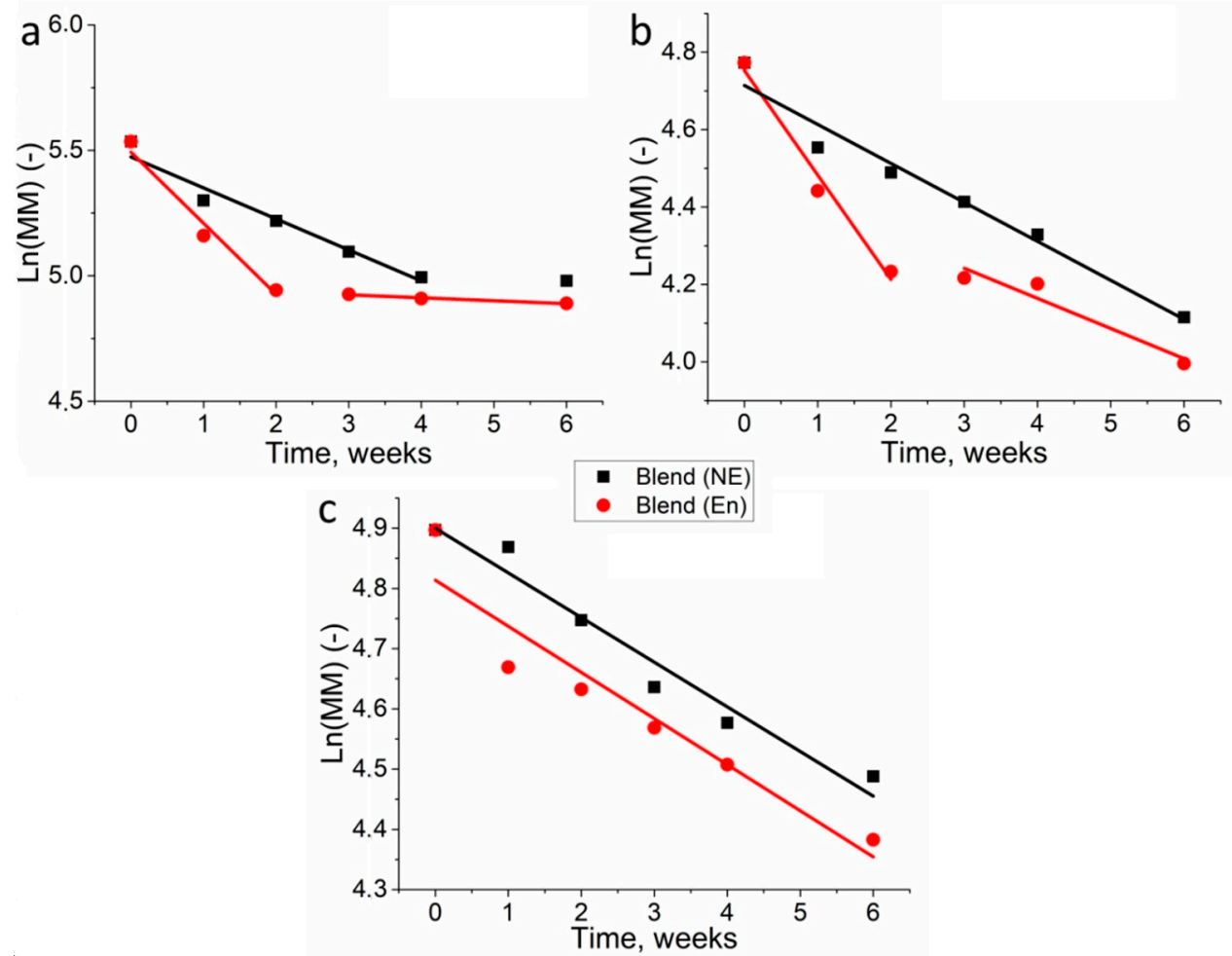

Figure 6. A linearized model of first-order kinetics applied on the degradation of PHB in phosphate buffer without lipase (NE) and phosphate buffer with lipase (E) (a), phosphate buffer without lipase and phosphate buffer with lipase (b), and $\mathrm{PHB} /$ PLA in phosphate buffer without lipase and phosphate buffer with lipase (c). 
Table 1. Kinetic model parameters and coefficients of determinations $\left(\mathrm{R}^{2}\right)$ for the degradation of PHB, PLA and PHB/PLA blend in phosphate buffer without lipase and phosphate buffer with lipase.

\begin{tabular}{|c|c|c|c|c|}
\hline \multirow{2}{*}{ Sample } & \multicolumn{2}{|c|}{ PBS } & \multicolumn{2}{|c|}{ Lipase } \\
\hline & $\mathrm{k}_{\mathrm{D}}\left(\right.$ Week $\left.^{-1}\right)$ & $\mathbf{R}^{2}$ & $\mathrm{k}_{\mathrm{D}}\left(\right.$ Week $\left.^{-1}\right)$ & $\mathbf{R}^{2}$ \\
\hline PHB & $012+0.01$ & 096 & $0.28 \pm 0.046$ & 0.97 \\
\hline РНВ & $0.12 \pm 0.01$ & 0.96 & $0.01 \pm 0.002 *$ & 0.98 \\
\hline PLA & $0.1 \pm 0.009$ & 0.97 & $0.26 \pm 0.035$ & 0.98 \\
\hline ILA & & 0.97 & $0.07 \pm 0.02 *$ & 0.93 \\
\hline PHB/PLA & $0.07 \pm 0.01$ & 0.97 & $0.07 \pm 0.007$ & 0.96 \\
\hline
\end{tabular}

*2nd sections of the curve with different rates of degradation. Explanations in the text.

The obtained data indicate different degradation kinetics of homopolymers and their blend. A similar kinetics of degradation was observed for PHB and PLA in lipase solution. In both cases, the greatest decrease in MM was observed during the first two weeks of incubation. In addition, the $\mathrm{k}_{\mathrm{D}}$ of both polymers was remarkably close. In the following days, the decomposition rate decreased several times. However, in case of the blend of these polymers, the kinetics of degradation was a linear throughout the experiment, both in lipase solution and in phosphate buffer.

The study of the degradation kinetics of various polymers also makes it possible to assess the presence of the autocatalysis process in the decomposition reaction. To evaluate the applicability of the specific model, the curves of degradation were calculated via the statistical correlation coefficients. In order to achieve this, the values 1/MM and $\ln (\mathrm{MM})$ were plotted against time, where $1 / \mathrm{MM}$ corresponds to a non-catalytic model and $\ln (\mathrm{MM})$ corresponds to an autocatalytic one. The correlation coefficients for the respective models are shown in Table 2.

Table 2. Assessment of the contribution of the autocatalysis process to the decomposition rate of PHB, PLA and PHB/PLA blend films.

\begin{tabular}{cccc}
\hline Degradation Model & Polymer Sample & $\begin{array}{c}\mathbf{R}^{2} \text { Nonautocatalic } \\
\text { Model }\end{array}$ & $\begin{array}{c}\mathbf{R}^{2} \text { Autocatalic } \\
\text { Model }\end{array}$ \\
\hline \multirow{3}{*}{ Non-enzymatic } & PHB & 0.91 & 0.85 \\
& PLA & 0.97 & 0.97 \\
& PHB/PLA & 0.87 & 0.84 \\
\hline \multirow{2}{*}{ Enzymatic } & PHB & 0.76 & 0.61 \\
& PLA & 0.90 & 0.83 \\
& PHB/PLA & 0.94 & 0.91 \\
\hline \multirow{2}{*}{ Cell-cultivating } & PHB & 0.95 & 0.93 \\
& PLA & 0.85 & 0.74 \\
& PHB/PLA & 0.97 & 0.98 \\
\hline
\end{tabular}

The data in Table 2 suggests that the autocatalysis process takes part in the decomposition of PLA in PBS and in the decomposition of the PHB/PLA blend.

To study the influence of seeded cells on polymers' degradation, the changes in corresponding properties of polymer films during cell culture on them were analyzed. The molecular weight of all polymers decreased during the cell cultivation on the films. As to the experiment, while being in solution, it was observed that the changes in homopolymers occurred nonlinearly. In the first week, there was a stronger decrease in MM in PLA-by $31 \%$, and in PHB - by $17 \%$, versus $6.5 \%$ in the PHB/PLA blend (Figure 7 ). 


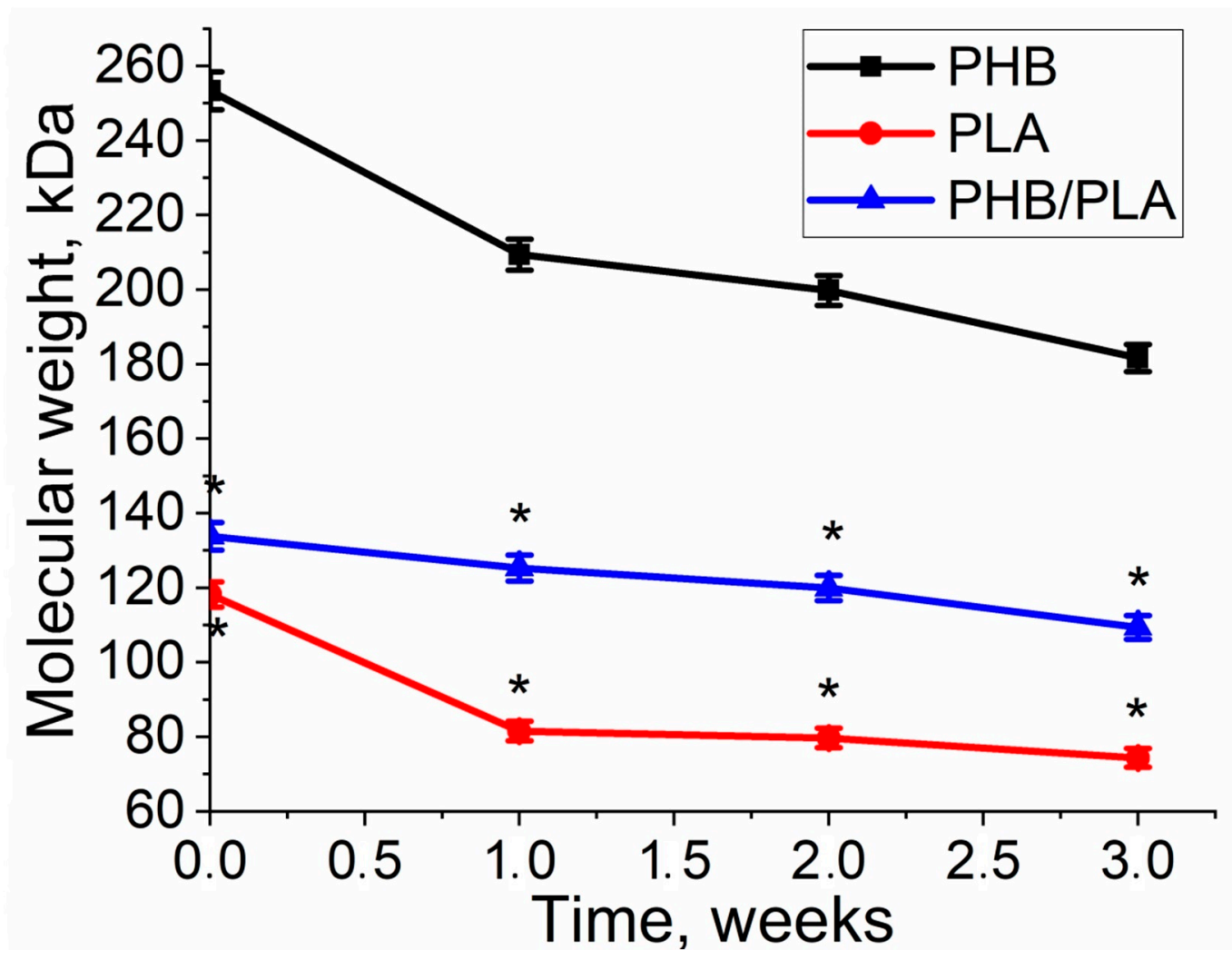

Figure 7. Molecular weight loss of polymers during cultivation of $3 \mathrm{~T} 3$ fibroblasts on the PHB, PLA, and PHB/PLA blend films. *-PLA \& PHB/PLA vs. PHB $p<0.05$.

The application of first-order kinetic model on the observed exponential decrease of molecular weight in time provided the value $\mathrm{k}_{\mathrm{D}}=(0.104 \pm 0.02)$ week $^{1}$ for PHB, $(0.1412 \pm 0.055)$ week $^{1}$ for PLA and $(0.065 \pm 0.064)$ week $^{1}$ for PHB/PLA blend for degradation during cell experiment. In this case, $\mathrm{k}_{\mathrm{D}}$ for PHB and PLA biodegradation kinetics was similar, whereas $k_{D}$ of PHB/PLA blend was significantly lower in comparison with two other homopolymers. However, the values of $k_{D}$ for PHB and PLA were closer to values of $k_{D}$ during non-enzymatic hydrolytic degradation than to enzymatic degradation. Noteworthy that $\mathrm{k}_{\mathrm{D}}$ of PHB/PLA blend was even the same for all experiments.

The contribution of autocatalysis was also evaluated (Table 2). High correlation coefficients for the non-autocatalytic and autocatalytic models correspond to the polymers PHB and PHB/PLA. This indicates the acceleration of the degradation process by means of autocatalysis. In the degradation of PLA, autocatalysis, in accordance with the coefficients, did not not take place ( 0.85 for non-autocatalytic and 0.74 for autocatalytic).

\subsection{Crystallinity Analysis}

Thermal properties of polymers (e.g., crystallinity $\left(\mathrm{X}_{\mathrm{c}}\right)$, melting temperature $\left(\mathrm{T}_{\mathrm{m}}\right)$ ), may encounter changes upon degradation process. The DSC curves of PLA/PHB blend with a heating rate of $10^{\circ} \mathrm{C} / \mathrm{min}$ is shown in Figure 8 . 


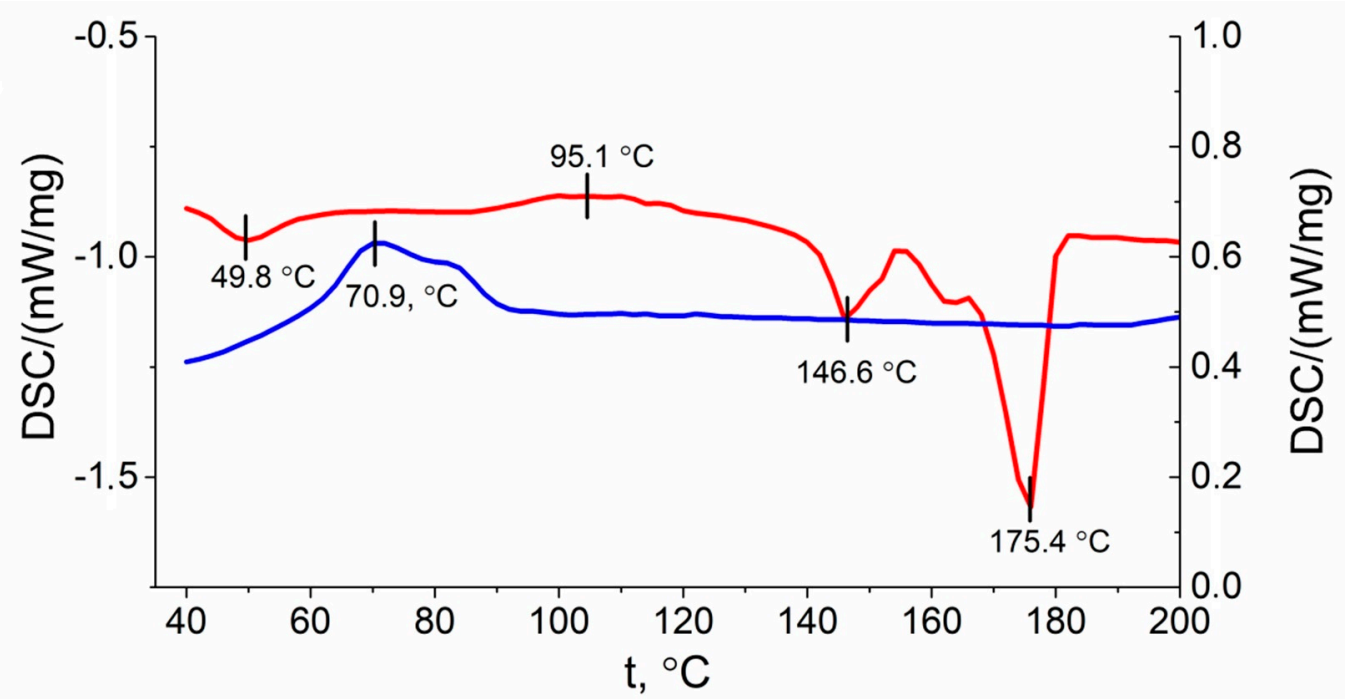

Figure 8. DSC curves of PLA/PHB obtained from second heating run (red line), cooling run (blue line).

Based on the DSC data, upon heating a peak in the glass transition temperature can be seen at $49.8{ }^{\circ} \mathrm{C}$ (represented as a red line in Figure 8). The peak of PLA crystallization was detected at $95.1^{\circ} \mathrm{C}$. After that the melting point peaks of PLA and PHB at temperatures of $146.6{ }^{\circ} \mathrm{C}$ and $175.4^{\circ} \mathrm{C}$ respectively were obtained. During sample cooling, the PHB crystallization peak was observed at $70.9^{\circ} \mathrm{C}$. These results indicate that the crystallinity and crystallization rate of PHB are much higher than PLA [26].

As shown in Table 3, PHB films maintained a relatively stable melting temperature. After 6 weeks PHB crystallinity with non-enzymatic degradation was slightly decreased, while PHB crystallinity after enzymatic degradation was slightly increased. The crystallinity of PLA films dropped from $34 \%$ to $29 \%$ for both enzymatic and non-enzymatic degradation (Table 3) in spite of the different changes in melting temperature. PHB component in blend had an increase in crystallinity after 6 weeks degradation, whereas the enzymatic degradation showed an increase in crystallinity, as opposed to non-enzymatic degradation. With respect to the PLA component, crystallinity was slightly increased after non-enzymatic degradation, and decreased after enzymatic degradation. Besides, the changes in melting temperature in PHB/PLA blend had a similar pattern with respect to pure PHB and PLA.

Table 3. DSC parameters of polymer films (degradation duration: 6 weeks).

\begin{tabular}{|c|c|c|c|c|c|}
\hline Polymer & Samples & $T_{m}(\mathrm{PHB}),{ }^{\circ} \mathrm{C}$ & $T_{m}$ (PLA), ${ }^{\circ} \mathrm{C}$ & $X_{c}(\mathrm{PHB}), \%$ & $X_{c}$ (PLA), \% \\
\hline \multirow{3}{*}{ PHB } & Fresh & 176.5 & - & 63.0 & - \\
\hline & $\mathrm{NE}$ & 175.0 & - & 58.6 & - \\
\hline & En & 176.1 & - & 64.0 & - \\
\hline \multirow{3}{*}{ PLA } & Fresh & - & 148.1 & - & 34.0 \\
\hline & $\mathrm{NE}$ & - & 153.4 & - & 29.2 \\
\hline & En & - & 147.0 & - & 29.5 \\
\hline \multirow{3}{*}{ PHB/PLA } & Fresh & 175.4 & 146.6 & 46.7 & 18.5 \\
\hline & NE & 175.2 & 151.3 & 52.1 & 21.5 \\
\hline & En & 174.8 & 147.0 & 66.3 & 13.2 \\
\hline
\end{tabular}

\subsection{Cell Viability Analysis}

Cell viability is an essential criterion assessing the biocompatibility of polymer films, where high viability value usually indicates better cell proliferation. In the first cell experiment, fresh films were used to evaluate the cell proliferation on the films from the three different polymers. As shown in Figure 9, 3T3 cells proliferated on all polymer films after 
2 weeks incubation. However, PLA and PHB/PLA blend had higher cell viability than $\mathrm{PHB}$, suggesting better cell proliferation on PLA and polymer blend films.

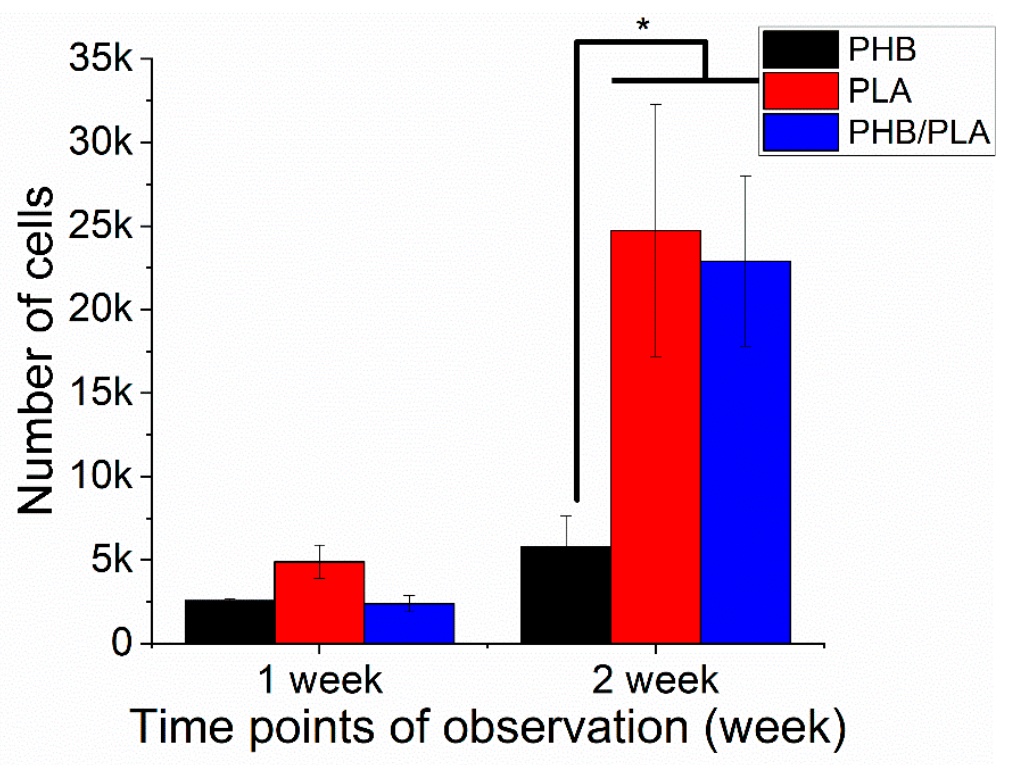

Figure 9. Cell viability test (cell experiment on fresh films). ${ }^{*}-p<0.05$.

To assess the interaction between degraded films and $3 \mathrm{~T} 3$ fibroblasts, the cells were seeded on degraded films followed by a viability test (Figure 10). The UV absorption value is proportional to cell viability, and higher absorption indicates better cell viability and proliferation. The results revealed that films experiencing different degradation durations had distinct cell viability values. For all three different polymer films, there was no significant difference in cell viability between 1st day and 3rd day incubation (Figure 10a-c). It can also be noted that, within the same type of polymer, films after 2 weeks' degradation demonstrated similar values to the films after 6 weeks degradation in spite of degradation type. However, cell viability varied drastically after $5 \mathrm{~d}$ 's incubation, which exhibited both in degradation and polymer types. For PHB (Figure 10a), films after 2 weeks' non-enzymatic degradation had the highest value of cell proliferation, while films after 6 weeks' degradation showed lower values of cell viability. In comparison to 1 day and 3 days incubation, cell viability value after 5 days had encountered a drastic increase.

PLA films showed a similar pattern to PHB after $5 \mathrm{~d}$ 's incubation (Figure 10b). A high level of cell proliferation (around $0.4 \times 10^{4}$ ) was observed on fresh-made films, films after 2 weeks non-enzymatic degradation and films after 6 weeks' enzymatic degradation. Unlike PLA and PHB, the blend after 5 days incubation exhibited a different pattern of cell viability with a relatively consistent value around $8 \times 10^{4}$, and the highest value was observed on films after 2 weeks' enzymatic degradation (Figure 10c). It should also be noted that cell proliferation remained relatively consistent within the same time points regardless of degradation durations and types of films. 


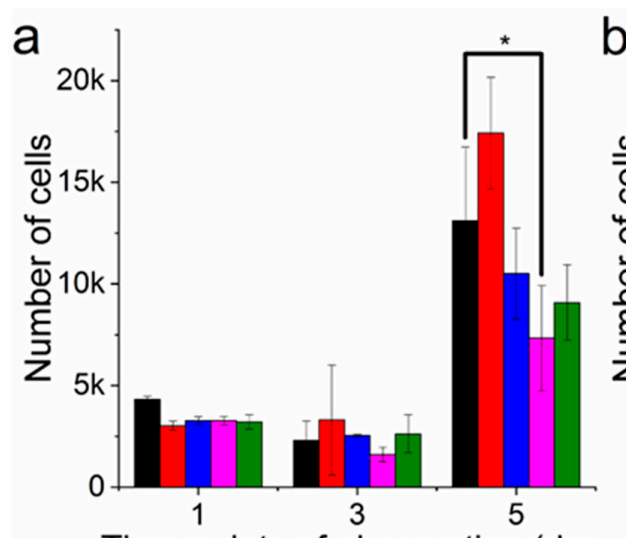

Time points of observation (day

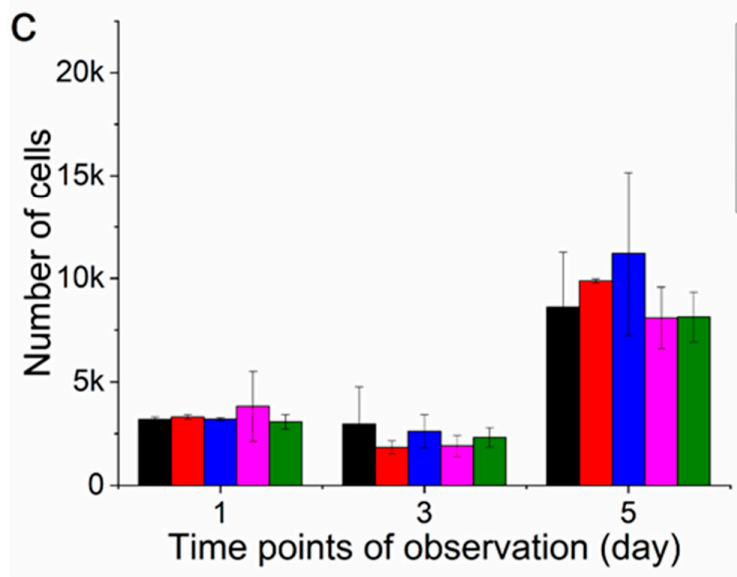

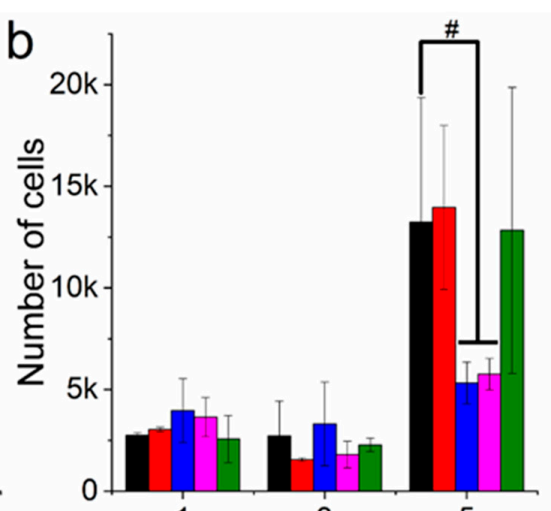

Time points of observation (day)

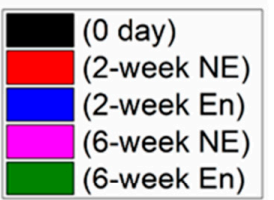

Figure 10. Cell proliferation on degraded films of PHB (a), PLA (b) and PHB/PLA blend (c) ${ }^{*}-p<0.05 ; \#-p<0.05$.

\subsection{Analysis of Surface Structure and Cell Distribution}

Scanning electron and fluorescence microscopy methods were utilized in order to further assess the changes in the structure of the film surface as well as cell distribution. Upon film degradation, surface erosion was observed, where the extent of the erosion varied among the polymer types. The samples used for SEM analysis were obtained from the cell experiment after one week's incubation. As shown in Figure 11, both PHB/PLA blend and PLA exhibited certain degree of surface erosion characterized by disruption of surface morphology, while the surface of PHB remained relatively smooth and intact. It can also be noted that the blend does not possess a homogeneous structure, where it contains round spherical structures. Cell proliferation on PLA and PHB/PLA blend film surfaces was observed to have a broad and relatively even distribution. Unlike PLA, cell distribution displayed a distinct pattern on PHB and PHB/PLA blend surface, which consists of isolated colonies with different sizes.

Polymer films undergo properties change as the degradation proceeds, which may influence the viability and distribution of seeded cells. Fluorescence microscopy was used to study cell viability and distribution on both fresh and degraded polymer films. The results revealed that $3 \mathrm{~T} 3$ cells proliferated on all polymer films after 5 days' incubation. On fresh films the surfaces were covered by a consecutive and dense layer of 3T3 fibroblasts (Figure 12). However, cell distribution on degraded films (42d's enzymatic degradation) displayed a distinctive pattern compared to fresh films, which is characterized by isolated colonies of different sizes. It can be noted that degraded PLA films had a relatively even cell distribution. Interestingly, there were small holes scattered across degraded PHB/PLA blend surface. 

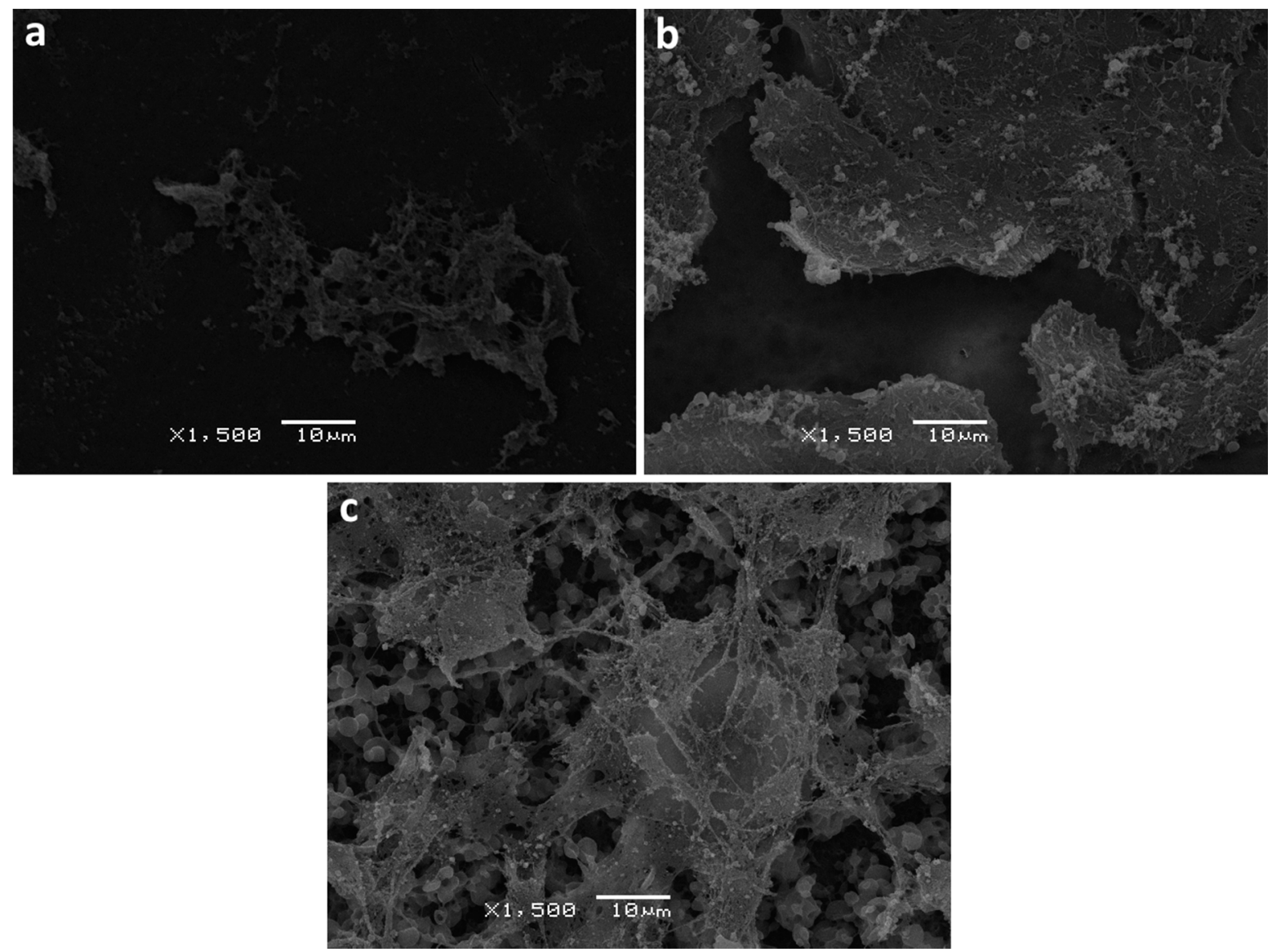

Figure 11. Surface analysis of PHB (a), PLA (b) and PHB/PLA blend (c) after 1-week 3T3 fibroblast cultivation on them $(\mathrm{SEM}, \times 1500)$.

One of the indicators of polymers use in drug delivery and tissue engineering is the analysis of the ability of the polymer surface to adsorb proteins. The degree of BSA adsorption ability was evaluated on the PHB, PLA, and PHB/PLA blend films. The polymer films incubated in PBS were observed to have a different protein adsorption, compared to the films incubated in a lipase solution (Figures S3 and S4, Supplemental Materials). Thus, 1 week films incubation in a PBS solution resulted in a decrease in the amounts of adsorbed protein. Subsequently, it resulted in increased amounts of adsorbed proteins. However, when the films were incubated in a lipase solution, an opposite trend was observed. After the first week, the amount of protein on the surface of the films initially increased and shortly after that the protein concentration dropped. The experiment and its results are described in more detail in the Supplementary Materials (Supplementary Materials Figure S2). 

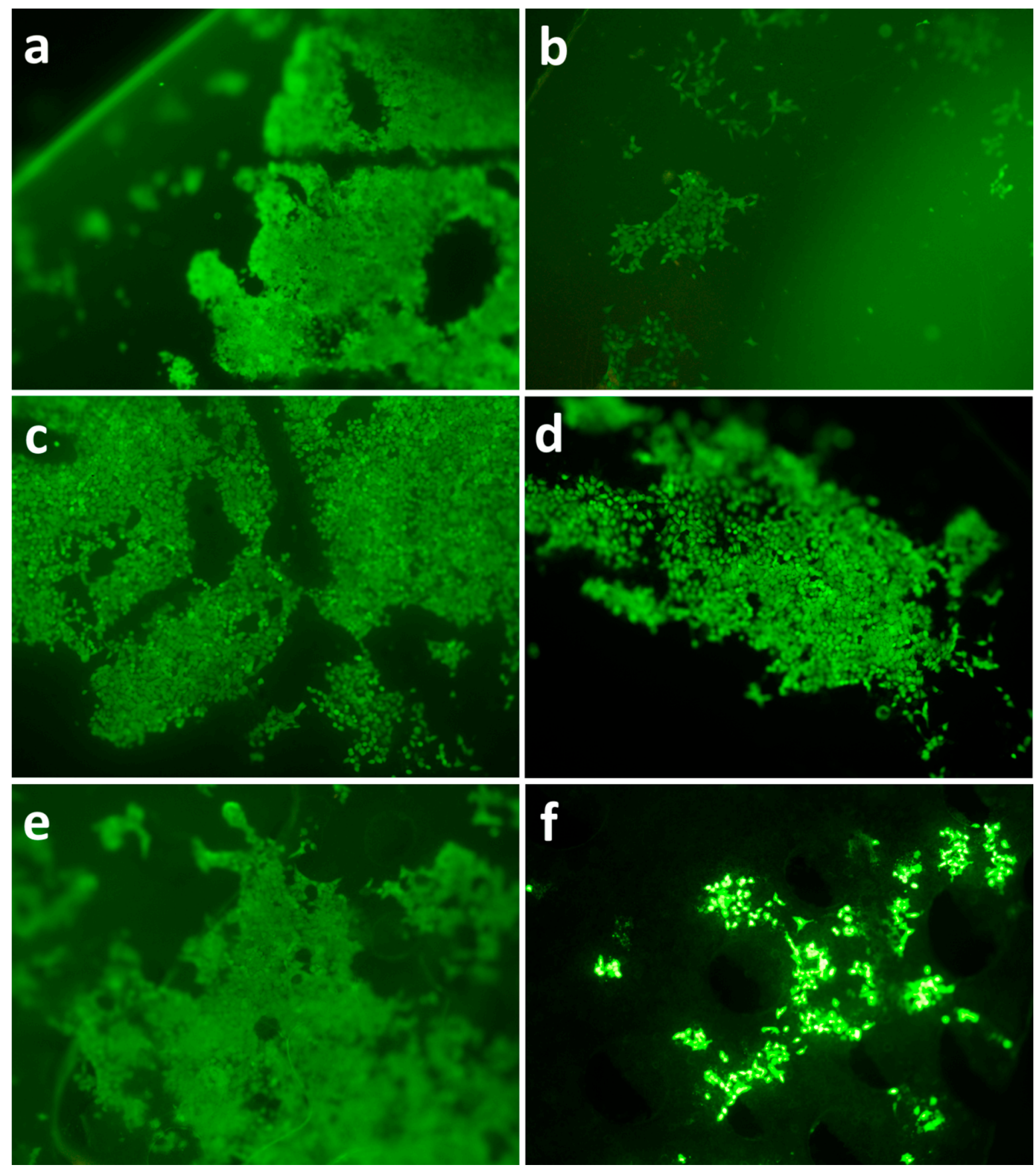

Figure 12. Cell proliferation at 5th day on degraded films from PHB (a,b), PLA (c,d), PHB/PLA blend (e,f); fresh films $(\mathbf{a}, \mathbf{c}, \mathbf{e})$ and 6-weeks after enzymatic degradation $(\mathbf{b}, \mathbf{d}, \mathbf{f})$.

\section{Discussion}

Weight loss is one of the most conspicuous features observed in polymer degradation, indicating the polymer destruction. Figure 2 reveals that PLA has a greater weight loss than PHB, which is in accordance with literature. It is connected with that PHB has high crystallinity [28,37]. Furthermore, weight loss of PHB has no significant differences between its enzymatic and non-enzymatic degradation.

Molecular weight loss serves as important indication of polymer degradation. Figure 3 reveals that enzymatic degradation induced a greater molecular weight loss than nonenzymatic degradation, which can be explained by involvement of lipase in accelerating the degradation rate. Researches also confirmed that enzymes, like lipase and depolymerase, 
are more efficient in contributing to the breakdown of polymer chains [38,39]. Although PLA had a smaller initial molecular weight value than PHB, it exhibited a higher loss value $(54 \%)$ after 6 weeks of enzymatic degradation, where according to the literature, PLA is more prone to degradation than PHB $[26,28]$.

The kinetic model parameter $\left(\mathrm{k}_{\mathrm{D}}\right)$ demonstrated interesting data. During PHB and PLA homopolymer decomposition in a lipase solution, the kinetics curves had two distinct stages of molecular weight change. At the first stage (the first 2 weeks of degradation) the rate of degradation was twice as high as during the following 4 weeks. This can be explained by the presence of an amorphous component in semicrystalline polymers. It was shown earlier that the amorphous component decomposes much faster than the crystalline one $[40,41]$. Autocatalysis is observed during the decomposition of PLA in a phosphate buffer (Table 2). The absence of this phenomenon during the enzymatic decomposition of PLA is explained by the higher rate of decomposition, at which autocatalysis is not observable. The static state of PHB between 4 and 6 week's degradation might result from the impediment imposed by the crystallized inner part, which was exposed to the buffer after depletion of amorphous outer regions. It was suggested that further crystallinity analysis may help to explain the unchanged state.

Thermal properties, such as crystallinity, serve as an important indicator of polymer degradation, where the properties changes vary among different polymers and copolymers [28]. It was reported that the rate of erosion of melt-crystallized films significantly decreased as the degree of crystallinity increased [39]. DSC analysis revealed (Table 2) that PHB remained at a constant melting temperature both in blend and pure PHB, which was also in accordance with literature [42]. The crystallinity of pure PHB displayed relatively small change after 6 weeks' degradation, suggesting that PHB films still maintained a relatively ordered crystalline structure, which further suggests that PHB had the lowest weight loss and degradation rate compared with the blend and PLA (Figure 7). Pure PLA exhibited reduced crystallinity after 6 weeks' degradation, which may indicate the erosion of crystalline phase.

Previous research also confirms that enzymes came into effect when the ordered structures of PHB were dismantled by initial degradation [43,44]. The slow degradation of PHB indicates that high polymer crystallinity restricts the effectiveness of enzymes, which slows down the degradation process. Enzyme cannot penetrate highly ordered structures of PHB films at this stage but can penetrate the amorphous phase of PHB and hydrolyze polymer chains. The high molecular weight loss of PHB is associated with cleavage of PHB chains in amorphous phase, which was earlier demonstrated by the work of Zhuikov et al. [45]. However, this effect of less susceptibility to degradation by enzymes at a later stage is also present for PLA films, whereas the rate of its degradation is much higher (Figure $6 b$ ).

The blend fabricated through mixing PHB and PLA was expected to demonstrate weight loss that would be an average of the value of its primary components PHB and PLA. However, the experimental results showed that blend underwent the highest weight loss after 6 weeks' enzymatic degradation. It was observed that the PHB/PLA films had a pronounced roughness and porosity after 6 weeks' enzymatic degradation, which supports the fact that the blend films degraded faster than PLA films following 6 weeks of enzymatic degradation. The unexpected data were obtained upon analysis of the change in the PHB/PLA blend molecular weight. The blending of PHB with PLA reduced the degradation rate and, turning out to have the smallest rate under both enzymatic and hydrolytic degradation. Unlike $\mathrm{k}_{\mathrm{D}}$ of PHB and PLA homopolymers, the $\mathrm{k}_{\mathrm{D}}$ of PHB/PLA blends stayed the same during both during enzymatic degradation and during lipasefree hydrolysis (Table 1). The curve had one relatively straight section (Figure 6c). This behavior can be attributed to a possible interaction between PHB and PLA within the mixture. The degradation rate of the blend is about 4-times less than the rate of the individual homopolymers at the first stage. Notably, the crystallinity degree of the polymers in the blend was also observed to be lower (Figure 2). The blend's $k_{D}$ value is close 
to the PLA $k_{D}$ value at the second stage of its degradation, which suggests that PLA could contribute to the blend's degradation at least during the late stages of the course of the experiment (3-6 weeks). The analysis of blend degradation curves showed that the correlation coefficients of both nonautocatalic and autocatalic models were quite close (Table 2), which suggests that the contribution of autocatalysis cannot be excluded. Thus, regarding the curve of PHB/PLA blend weight loss during its enzymatic degradation (Figure 1), we can assume that this effect may be due to the removal of low-molecular degradation products, whereas they are retained in the polymer matrices of PHB and PLA. This can lead to a more uniform and a less pronounced degradation process in the blend.

PHB/PLA blend possessed a more complicated pattern with an increase in crystallinity in PHB component, which may have signified a temporal positive impact of the degradation stages of the initial erosion of amorphous phases on the crystallinity. According to the DSC curve (Figure 5), the PHB and PLA polymers were immiscible. The characteristic peaks are well distinguishable for each of the polymers. The glass transition temperature and the melting temperature for PLA were found to be $48.8^{\circ} \mathrm{C}$ and $146.6^{\circ} \mathrm{C}$, respectively. Moreover, the peak of PLA crystallization $\left(95.1^{\circ} \mathrm{C}\right)$ was observed. This peak is not always visually accessible upon use of polymer mixtures [26]. The typical melting point peak of PHB was at $175.4^{\circ} \mathrm{C}$, and in contrast to the PLA, the crystallization temperature via cooling was at 70.9 degrees. It was shown also that PLA and PHB are immiscible. The blending of these polymers may compromise the ordered solid structures of polymers, making the blend vulnerable to the enzymatic attack $[26,46]$.

These data indicate that the film represents inclusions from PHB and PLA, located randomly throughout the volume. The PLA component in blend had lower crystallinity in enzymatic degradation than that in non-enzymatic degradation, which accounts for highest weight loss of the blend upon enzymatic degradation. It is worth noting that in comparison to pure polymers, both PLA and PHB components in blend experienced a decrease in crystallinity, which is related to the immiscibility and structure disruption between PLA and PHB. In this research, we speculated that following initial erosion of ordered regions, enzymes were capable of penetrating inside the regions with greater fragility and immiscibility that were formed by combination of PHB and PLA, therefore accelerating the degradation rate. Upon suggesting that the polymers are in fact immiscible, this implies a potential increase in the polymer molecules' surface area, which furthermore may elevate the degradation rate. Surprisingly, this immiscible nature of PHB/PLA blend leads to enzymatic degradation with uniform rate, since enzymes better penetrate into the unorganized polymer blend matrix, especially at the late stage of degradation process, in comparison with the pure polymers, their components: PHB and PLA.

Analysis of the particulate degradation products from polymer films after first week showed very low concentrations of the released particles. The highest concentration was achieved only during PHB films degradation, which was in agreement with our results. This explains the largest decrease in PHB molecular weight in the first week of degradation. After the second week of incubation in water, it became possible to detect nanoparticles. The highest concentrations correspond to particles with a size of $340 \mathrm{~nm}$ for PHB, $300 \mathrm{~nm}$ for PLA, and 340-530 $\mathrm{nm}$ for a composite. The particles of about $200 \mathrm{~nm}$ were discovered after the first week of PHB incubation. During this time polymers of this type not have enough time to undergo the decomposition process due to their hydrophobicity. Therefore, the most accurate explanation for this observation is the washing out of oligomers and unbound polymer from the bulk of the product. During the two weeks of incubation, which in turn elevates the particle fraction and leads to the formation of the particle peaks of the order of $10 \mathrm{~nm}$. Particles with the size over $5500 \mathrm{~nm}$ are considered an artifact, arising from an insufficient centrifugation, as well as the initial fraction of the polymer, which gives rise to smaller nanoparticles.

Films seeded with cells may have different changes in properties compared to pure films. The molecular weight analysis showed that the growth of 3T3 cells on PLA and blend helped to accelerate the degradation rate, which may have been influenced by the cells' 
metabolism. Moreover, 3T3 cells had a wider distribution across PLA's and the blend's surface (confirmed by images obtained from SEM and fluorescence microscope). The PHB degradation has shown an opposite trend, where no significant difference in cell experiment and degradation experiment, which was confirmed by a relatively unaffected PHB surface. It was suggested that the highly ordered structure of PHB restricts the possible effects imposed by cell metabolism in the initial stage of degradation. Besides, it can also depend on the overall number of cells grown on films at each time point, which might require further investigation to reveal the distinctive pattern of PHB.

It can be observed that PLA had greater molecular weight loss in cell experiment than in non-enzymatic degradation, while molecular weight loss of PHB and PHB/PLA blend in non-enzymatic degradation was higher than in cell experiment (Table 4).

Table 4. The comparison of molecular weight loss after 2 weeks in the non-enzymatic, enzymatic, and cell growth degradation models.

\begin{tabular}{cccc}
\hline \multirow{2}{*}{ Polymer Films } & \multicolumn{3}{c}{ Molecular Weight Loss, \% } \\
\cline { 2 - 4 } & $\begin{array}{c}\text { Enzymatic } \\
\text { Degradation }\end{array}$ & $\begin{array}{c}\text { Non-Enzymatic } \\
\text { Degradation }\end{array}$ & Cell Experiment \\
\hline PHB & $45 \pm 2.2$ & $27 \pm 1.3$ & $21 \pm 1$ \\
PLA & $42 \pm 2.1$ & $25 \pm 1.2$ & $33 \pm 1.6$ \\
PHB/PLA & $23 \pm 1.2$ & $14 \pm 0.7$ & $10 \pm 0.5$ \\
\hline
\end{tabular}

The molecular weight loss of enzymatic experiment was higher than cell experiment. A possible explanation for this effect is that upon enzymatic decomposition, the enzyme is provided with a large polymer area, which leads to an accelerated degradation. Cells also accelerate the degradation of polymers but act locally. In contrast to cell-based components, a higher PHB degradation rate in the non-cell (PBS) can be explained by the facilitated leakage of the solutions into the polymer matrix. Cells spread out on the surface of the polymer and, and show a smaller effect on it due to the hydrophobicity of the polymer. In cell investigation PHB/PLA blend also demonstrated more uniform and slower degradation process than PHB and PLA that can be explained by the uneven ultrastructure of the polymer blend matrix and, therefore, its better availability for cleavage by cellular enzymes.

Cell viability test is widely used for evaluation of cell proliferation on polymer films [35,47]. Higher cell viability value indicates better cell proliferation and adhesion. The blend and PLA had higher cell viability values after 2 weeks incubation, which implies better cell adhesion and proliferation (Figure 9). It is also suggested that PLA and blend films display better interaction with 3T3 cells, which is confirmed by images obtained from SEM. This difference in cell viability between polymers may be related with a combination of favorable properties of polymer film surface, such as hydrophilicity and microstructure, which requires further investigation.

Cell experiment on degraded films revealed that there is no significant difference in cell viability between $1 \mathrm{~d}$ and $3 \mathrm{~d}$ 's incubation, which may be explained by a small size of films and insufficient incubation time. After 5d's incubation, it was observed that films with different durations of degradation exhibited distinctive cell viability values. For PHB, fresh films and films after 2 weeks' degradation had higher cell viability than films with 6 weeks' degradation, indicating that the degradation duration may have shown a negative correlation with cell proliferation. PLA had a similar cell viability pattern as PHB after 5d's incubation the only exception with the films undergoing a 6 week enzymatic degradation, which showed higher cell viability. It was suggested that there is no linear correlation between degradation duration and cell viability. Interestingly, the blend displayed relatively stable cell viability in spite of films with different degree of degradation, which indicates that the biocompatability of PHB/PLA blend was retained after 6 week degradation. This effect is also correspondent with more uniform degradation process of the blend. 
It was reported in literature that the surface structure of polymers can influence proliferation and adhesion of cells and also that it it depends on specific microstructures of certain biopolymers $[18,47]$. Images obtained from scanning electron microscope revealed that the blend had higher degree of surface erosion (Figure 11c), which can be explained by the fact that the polymer blending disrupted the ordered structure of pure PLA and PHB, making the blend prone to degradation. PHB retained its relatively smooth and intact surface, which can be attributed to its high crystallinity and high viscosity. The difference in cell distribution may be related to the polymer's initial surface properties, which influenced cell distribution pattern during the experiment. Meanwhile, it also could be a result of interaction between cells and polymers, which impose a mutual effect on both degradation course and cell proliferation.

The micro- and nanoparticles' analyses during the degradation of polymers in milli-Q water showed presence of polymer particles in solution with the following size distributions: PHB: 3, 10, $340 \mathrm{~nm}$. PLA: 0.9, $300 \mathrm{~nm}$ and for PHB $\backslash$ PLA: 4.1, 340-530 nm. Particle sizes of $300-530 \mathrm{~nm}$ can correspond to polymer particles that are not bound to the polymer matrix and released from the bulk of the polymer film. Nanoparticles with size range of 0.9 to $4.1 \mathrm{~nm}$ were also observed and were suggested to be a decomposed part of the polymer.

According to the results (Figure S5), cell proliferation on centrifuged samples did not differ from cells in the control medium, which suggests that the products of PHB degradation are not toxic for them, whereas non-centrifuged PHB powder dispersion in medium inhibited cell proliferation. However some authors implied that PHB nanoparticles do have a toxic effect [33].

The fluorescence microscopy data shows that cells exhibited better proliferation on fresh made films after $5 \mathrm{~d}$ 's incubation, which indicates that all polymer films were biocompatible. It was also observed that degraded films of blend and PHB had different cell distribution patterns compared to PLA, which were characterized by a combination of large and small colonies. We speculated that this difference may be related to surface structure and molecular weight. The blend suffered severe surface erosion after 6 weeks' degradation, which disrupted and restricted cell proliferation to isolated areas with different scales. Although PHB did not experience a high degree of surface erosion after 6 weeks' degradation, it experienced the highest molecular weight loss, which could be a factor causing the scattered pattern of cell distribution.

Surprisingly, the uneven distribution of cells on polymer films can also be the reason for their slower and more uniform degradation. It was suggested also that the information about cell distribution patterns can be of great benefits for designing 3D-scaffolds seeded with cells for tissue and organ repair.

In bacterial cells, PHB is accumulated in special granules-carbonosomes. It was shown that PHB in such granules is at amorphous condition, which is maintained by a series of PHB-binding proteins [48]. Such an amorphous conformation of PHB allows the bacterial cell to use this biopolymer as a carbon source for its vital functions. The blending of PHB with PLA can be, with some reservations, a prospective tool to mimic a natural irregular conformation of PHB in bacterial carbonosomes. This approach can help to achieve the desired kinetics of polymer biodegradation for its application in regenerative medicine and tissue engineering.

\section{Conclusions}

It was shown that PLA films lost the mass and molecular weight faster than PHB, which was consistent with the literature data $[26,28]$. In both polymers there was a twostage pattern in the change of the enzymatic degradation rate and a one-stage pattern for non-enzymatic degradation rate. In the PHB/PLA blend the aforementioned pattern was not observed: the blend underwent a slower and more uniform one-stage process of enzymatic degradation. Enzymatic degradation significantly accelerated the degradation rate of all polymers compared to non-enzymatic hydrolytic degradation. The PHB degraded slower, which indicates its greater stability. According to the DSC results, PHB and PLA 
did not mix during the manufacture of the composite. We propose that the immiscible nature of PHB/PLA blend can be the reason for its greater stability during enzymatic degradation, due to possible better enzymes penetration into the unorganized polymer matrix of the blend, whereas the highly ordered structure of PHB and PLA severely limited enzyme penetration.

Studies of the effect of cell growth on the film surface showed that the viability of MSCs growing on PHB/PLA was not influenced at the time of enzymatic and non-enzymatic degradation of polymer films, while there were large differences in cell growth on both PHB and PLA films at different durations. The blend and PLA films exhibited a certain degree of surface erosion characterized by disruption of surface morphology, while the surface of PHB remained relatively smooth and intact. It was associated with the uneven distribution of cells (in form of large and small colonies) on polymer film surface. In cell growth studies PHB/PLA blend also demonstrated a more uniform degradation process with lower rate than its polymer components, PHB and PLA. We propose that it also can be linked to the unorganized structure of the blend's polymer matrix.

The size of particles released from polymer films can be divided into two groups: nanoparticles ( 0.9 to $4 \mathrm{~nm}$ ) and submicroparticles ( $300-530 \mathrm{~nm}$ ). The detection of these particles confirms the hypothesis about the release of oligomers and unbound polymer fragments from the bulk of polymer film, leading to a significant mass reduction of the films and $\mathrm{MM}$ at the initial stages of polymer degradation. It is possible that the polymeric biodegradation products can have an additional effect on growth of MSC and 3T3 fibroblasts upon their culture on polymer films.

As a result, the irregular and imperfect structure of the matrix of biodegradable polymer blends is not a limiting factor for their biomedical use. It is not necessary to always manufacture perfectly mixed polymer composites to achieve their biodegradation with appropriate kinetics. Nevertheless, novel techniques should be developed that will allow scientists to control the irregular polymer structure. Moreover, it can be a biomimetic approach for designing a natural irregular conformation of PHB to achieve the controlled kinetics of polymer biodegradation in human tissues. It allows to create e.g., biodegradable scaffolds with desired properties for regenerative medicine and tissue engineering.

Supplementary Materials: The following are available online at https:/ / www.mdpi.com/2073-4 360/13/1/108/s1, Figure S1. The viscosity loss of polymer films during their in vitro degradation. Figure S2. The viscosity loss of polymer films during cell growth on them. Figure S3. BSA absorption on PHB, PLA, and PHB/PLA blend films (after non-enzymatic degradation). Figure S4. BSA absorption on PHB, PLA, and PHB/PLA blend films (after enzymatic degradation). Figure S5. Evaluation of MSC proliferation in the media containing particulate degradation products of PHB by XTT on the 1st, 5 th and 7 th days of cell incubation. Data presented as mean $\pm \mathrm{SD},{ }^{*}-p<0.05$ (vs. Powder group). Figure S6. Surface analysis of after 1-week 3T3 fibroblast cultivation on PHB/PLA blend film. Figure S7. Surface analysis of after 1-week 3T3 fibroblast cultivation on PLA film. Table S1. The comparison of viscosity loss after 2 weeks of cell growth on PHB, PLA, and PHB/PLA films.

Author Contributions: Conceptualization, V.A.Z.; methodology, V.A.Z., A.P.B., T.K.M., V.V.V., R.A.S., M.A.S., E.A.A., G.A.B.; validation, A.P.B.; investigation, V.A.Z., Y.W., T.K.M., I.V.D., D.V.C., E.A.A.; resources, T.K.M., G.A.B.; data curation, A.P.B.; writing—original draft preparation, V.A.Z., Y.V.Z., Y.W.; writing-review and editing, A.P.B., R.A.S., N.V.B., M.A.S.; supervision, A.P.B., K.V.S.; project administration, A.P.B., K.V.S. All authors have read and agreed to the published version of the manuscript.

Funding: This work was supported by the Russian Science Foundation, project No 20-64-47008 (parts on the study of polymer films degradation in vitro), by Russian Foundation for Basic Research, project No 20-54-00021 (parts on the study of 3T3-NIH fibroblast growth on the polymer films after their degradation), and was carried out within the framework of government assignment of the Ministry of Science and Higher Education of the Russian Federation (the part of MSC growth study). The equipment used in this work was from the User Facilities Center of M.V. Lomonosov Moscow State University (including the FACSAria SORP complex, the scanning electron microscopes, Nano Spray Drier B-90, the facility system for the production of polymer micro- and nanoparticles etc.) and the User Facilities Center of Research Center of Biotechnology of Russian Academy of Sciences. 
Institutional Review Board Statement: Not applicable.

Informed Consent Statement: Not applicable.

Data Availability Statement: Data sharing not applicable.

Conflicts of Interest: The authors declare no conflict of interest.

\section{References}

1. Rasal, R.M.; Janorkar, A.V.; Hirt, D.E. Poly(lactic acid) modifications. Prog. Polym. Sci. 2010, 35, 338-356. [CrossRef]

2. Khanna, S.; Srivastava, A.K. Recent advances in microbial polyhydroxyalkanoates. Process. Biochem. 2005, 40, 607-619. [CrossRef]

3. Mokhtarzadeh, A.; Alibakhshi, A.; Hejazi, M.; Omidi, Y.; Dolatabadi, J.E.N. Bacterial-derived biopolymers: Advanced natural nanomaterials for drug delivery and tissue engineering. TrAC Trends Anal. Chem. 2016, 82, 367-384. [CrossRef]

4. Lenz, A.R.W.; Marchessault, R.H. Bacterial Polyesters: Biosynthesis, Biodegradable Plastics and Biotechnology. Biomacromolecules 2005, 6, 1-8. [CrossRef] [PubMed]

5. Rehm, B.H.A. Bacterial polymers: Biosynthesis, modifications and applications. Nat. Rev. Genet. 2010, 8, 578-592. [CrossRef]

6. Volova, T.G.; Kiselev, E.G.; Shishatskaya, E.; Zhila, N.; Boyandin, A.N.; Syrvacheva, D.A.; Vinogradova, O.N.; Kalacheva, G.S.; Vasiliev, A.D.; Peterson, I.V. Cell growth and accumulation of polyhydroxyalkanoates from CO 2 and H 2 of a hydrogen-oxidizing bacterium, Cupriavidus eutrophus B-10646. Bioresour. Technol. 2013, 146, 215-222. [CrossRef]

7. Bonartseva, G.A.; Zharkova, I.I.; Yakovlev, S.G.; Myshkina, V.L.; Mahina, T.K.; Voinova, V.V.; Zernov, A.L.; Zhuikov, V.A.; Akoulina, E.A.; Ivanova, E.V.; et al. Biosynthesis of poly(3-hydroxybutyrate) copolymers by Azotobacter chroococcum 7B: A precursor feeding strategy. Prep. Biochem. Biotechnol. 2016, 47, 173-184. [CrossRef]

8. Zhang, J.; Shishatskaya, E.I.; Volova, T.G.; Silva, L.F.; Chen, G.-Q. Polyhydroxyalkanoates (PHA) for therapeutic applications. Mater. Sci. Eng. C 2018, 86, 144-150. [CrossRef]

9. Możejko-Ciesielska, J.; Kiewisz, R. Bacterial polyhydroxyalkanoates: Still fabulous? Microbiol. Res. 2016, 192, 271-282. [CrossRef]

10. Kimura, Y.; Shirotani, K.; Yamane, H.; Kitao, T. Ring-opening polymerization of 3(S)-[(benzyloxycarbonyl)methyl]-1,4-dioxane-2,5dione: A new route to a poly(.alpha.-hydroxy acid) with pendant carboxyl groups. Macromology 1988, 21, 3338-3340. [CrossRef]

11. Auras, R.; Harte, B.R.; Selke, S. An Overview of Polylactides as Packaging Materials. Macromol. Biosci. 2004, 4, 835-864. [CrossRef] [PubMed]

12. Ray, S.S.; Okamoto, M. Biodegradable Polylactide and Its Nanocomposites: Opening a New Dimension for Plastics and Composites. Macromol. Rapid Commun. 2003, 24, 815-840. [CrossRef]

13. Schugens, C.; Grandfils, C.; Jerome, R.; Teyssié, P.; Delree, P.; Martin, D.; Malgrange, B.; Moonen, G. Preparation of a macroporous biodegradable polylactide implant for neuronal transplantation. J. Biomed. Mater. Res. 1995, 29, 1349-1362. [CrossRef] [PubMed]

14. Ramot, Y.; Haim-Zada, M.; Domb, A.J.; Nyska, A. Biocompatibility and safety of PLA and its copolymers. Adv. Drug Deliv. Rev. 2016, 107, 153-162. [CrossRef]

15. Karahaliloğlu, Z.; Demirbilek, M.; Şam, M.; Sağlam, N.; Mızrak, A.K.; Denkbaş, E.B.; Mizrak, A.K. Surface-modified bacterial nanofibrillar PHB scaffolds for bladder tissue repair. Artif. Cells Nanomed. Biotechnol. 2014, 44, 74-82. [CrossRef]

16. Zhijiang, C.; Yi, X.; Haizheng, Y.; Jia, J.; Liu, Y. Poly(hydroxybutyrate)/cellulose acetate blend nanofiber scaffolds: Preparation, characterization and cytocompatibility. Mater. Sci. Eng. C 2016, 58, 757-767. [CrossRef]

17. Sin, M.C.; Tan, I.K.P.; Annuar, M.S.M.; Gan, S.N. Thermal behaviour and thermodegradation kinetics of poly(vinyl chloride) plasticized with polymeric and oligomeric medium-chain-length poly(3-hydroxyalkanoates). Polym. Degrad. Stab. 2012, 97, 2118-2127. [CrossRef]

18. Senatov, F.; Anisimova, N.; Kiselevskiy, M.; Kopylov, A.; Tcherdyntsev, V.; Maksimkin, A. Polyhydroxybutyrate/Hydroxyapatite Highly Porous Scaffold for Small Bone Defects Replacement in the Nonload-bearing Parts. J. Bionic Eng. 2017, 14, 648-658. [CrossRef]

19. Gupta, B.; Revagade, N.; Hilborn, J. Poly(lactic acid) fiber: An overview. Prog. Polym. Sci. 2007, 32, 455-482. [CrossRef]

20. Sawyer, D.J. Bioprocessing-No Longer a Field of Dreams. In Proceedings of the IUPAC Polymer Conference on the Mission and Challenge of Polymer Science and Technology, Kyoto, Japan, 2-5 December 2002; Volume 201, pp. $271-282$.

21. Athanasiou, K.A. Sterilization, toxicity, biocompatibility and clinical applications of polylactic acid/ polyglycolic acid copolymers. Biomaterials 1996, 17, 93-102. [CrossRef]

22. Zhao, K.; Deng, Y.; Chen, J.C.; Chen, G.-Q. Polyhydroxyalkanoate (PHA) scaffolds with good mechanical properties and biocompatibility. Biomaterials 2003, 24, 1041-1045. [CrossRef]

23. JunLohbf, X.; Loh, X.J. Water soluble polyhydroxyalkanoates: Future materials for therapeutic applications. Chem. Soc. Rev. 2015, 44, 2865-2879. [CrossRef]

24. Silverman, T.; Naffakh, M.; Marco, C.; Ellis, G.J. Morphology and thermal properties of biodegradable poly(hydroxybutyrate-cohydroxyvalerate)/tungsten disulphide inorganic nanotube nanocomposites. Mater. Chem. Phys. 2016, 170, 145-153. [CrossRef]

25. Obruca, S.; Sedlacek, P.; Mravec, F.; Samek, O.; Marova, I. Evaluation of 3-hydroxybutyrate as an enzyme-protective agent against heating and oxidative damage and its potential role in stress response of poly(3-hydroxybutyrate) accumulating cells. Appl. Microbiol. Biotechnol. 2015, 100, 1365-1376. [CrossRef] [PubMed]

26. Zhang, M.; Thomas, N.L. Blending polylactic acid with polyhydroxybutyrate: The effect on thermal, mechanical, and biodegradation properties. Adv. Polym. Technol. 2011, 30, 67-79. [CrossRef] 
27. Furukawa, T.; Sato, H.; Murakami, R.; Zhang, J.; Duan, Y.; Noda, I.; Ochiai, S.; Ozaki, Y. Structure, Dispersibility, and Crystallinity of Poly(hydroxybutyrate)/Poly(l-lactic acid) Blends Studied by FT-IR Microspectroscopy and Differential Scanning Calorimetry. Macromolecules 2005, 38, 6445-6454. [CrossRef]

28. Abdelwahab, M.A.; Flynn, A.; Chiou, B.-S.; Imam, S.H.; Orts, W.J.; Chiellini, E. Thermal, mechanical and morphological characterization of plasticized PLA-PHB blends. Polym. Degrad. Stab. 2012, 97, 1822-1828. [CrossRef]

29. Arrieta, M.P.; Fortunati, E.; Dominici, F.; López, J.; Kenny, J.M. Bionanocomposite films based on plasticized PLA-PHB/cellulose nanocrystal blends. Carbohydr. Polym. 2015, 121, 265-275. [CrossRef]

30. Zhao, Q.; Cheng, G.; Song, C.; Zeng, Y.; Tao, J.; Zhang, L. Crystallization behavior and biodegradation of poly(3-hydroxybutyrate) and poly(ethylene glycol) multiblock copolymers. Polym. Degrad. Stab. 2006, 91, 1240-1246. [CrossRef]

31. Masood, F.; Aziz, M.; Haider, H.; Shakil, O.; Yasin, T.; Hameed, A. Biodegradation of gamma irradiated poly-3hydroxybutyrate/sepiolite nanocomposites. Int. Biodeterior. Biodegrad. 2018, 126, 1-9. [CrossRef]

32. Bonartseva, G.A.; Zharkova, I.I.; Yakovlev, S.G.; Myshkina, V.L.; Makhina, T.K.; Zernov, A.L.; Kudryashova, K.S.; Feofanov, A.V.; Akulina, E.A.; Ivanova, E.V.; et al. 3D-Scaffolds from Poly(3-hydroxybutyrate)Poly(ethylene glycol) Copolymer for Tissue Engineering. J. Biomater. Tissue Eng. 2016, 6, 42-52. [CrossRef]

33. González-Pleiter, M.; Tamayo-Belda, M.; Pulido-Reyes, G.; Amariei, G.; Leganés, F.; Rosal, R.; Fernández-Piñas, F. Secondary nanoplastics released from a biodegradable microplastic severely impact freshwater environments. Environ. Sci. Nano 2019, 6, 1382-1392. [CrossRef]

34. Zheng, Z.; Bei, F.-F.; Tian, H.-L.; Chen, G.-Q. Effects of crystallization of polyhydroxyalkanoate blend on surface physicochemical properties and interactions with rabbit articular cartilage chondrocytes. Biomaterials 2005, 26, 3537-3548. [CrossRef] [PubMed]

35. Bonartseva, G.A.; Zharkova, I.I.; Voinova, V.; Kuznetsova, E.S.; Zhuikov, V.A.; Makhina, T.K.; Myshkina, V.L.; Potashnikova, D.; Chesnokova, D.; Khaydapova, D.D.; et al. Poly(3-hydroxybutyrate)/poly(ethylene glycol) scaffolds with different microstructure: The effect on growth of mesenchymal stem cells. 3 Biotech 2018, 8, 328. [CrossRef]

36. Kovalcik, A.; Obruca, S.; Kalina, M.; Machovský, M.; Enev, V.; Jakesova, M.; Sobkova, M.; Marova, I. Enzymatic Hydrolysis of Poly(3-Hydroxybutyrate-co-3-Hydroxyvalerate) Scaffolds. Materials 2020, 13, 2992. [CrossRef]

37. Zaheer, M.R.; Kuddus, M. PHB (poly- $\beta$-hydroxybutyrate) and its enzymatic degradation. Polym. Adv. Technol. 2018, 29, 30-40. [CrossRef]

38. Tokiwa, Y.; Suzuki, T. Hydrolysis of copolyesters containing aromatic and aliphatic ester blocks by lipase. J. Appl. Polym. Sci. 1981, 26, 441-448. [CrossRef]

39. Numata, K.; Abe, H.; Iwata, T. Biodegradability of Poly(hydroxyalkanoate) Materials. Materials 2009, 2, 1104-1126. [CrossRef]

40. Zhuikov, V.A.; Bonartseva, G.A.; Makhina, T.K.; Myshkina, V.L.; Voinova, V.; Bonartseva, G.A.; Shaitan, K.V. Hydrolytic Degradation of Poly(3-Hydroxybutyrate) and Its Copolymer with 3-Hydroxyvalerate of Different Molecular Weights in vitro. Biophysics 2018, 63, 169-176. [CrossRef]

41. Sudesh, K.; Abe, H.; Doi, Y. Synthesis, structure and properties of polyhydroxyalkanoates: Biological polyesters. Prog. Polym. Sci. 2000, 25, 1503-1555. [CrossRef]

42. Rebia, R.A.; Rozet, S.; Tamada, Y.; Tanaka, T. Biodegradable PHBH/PVA blend nanofibers: Fabrication, characterization, in vitro degradation, and in vitro biocompatibility. Polym. Degrad. Stab. 2018, 154, 124-136. [CrossRef]

43. Mochizuki, M.; Hirami, M. Structural effects on the biodegradation of aliphatic polyesters. Polym. Adv. Technol. 1997, 8, 203-209. [CrossRef]

44. Hocking, P.J.; Marchessault, R.H.; Timmins, M.R.; Lenz, R.W.; Fuller, R.C. Enzymatic Degradation of Single Crystals of Bacterial and Synthetic Poly( $\beta$-hydroxybutyrate). Macromolecules 1996, 29, 2472-2478. [CrossRef]

45. Zhuikov, V.A.; Zhuikova, Y.V.; Makhina, T.K.; Myshkina, V.L.; Rusakov, A.; Useinov, A.; Voinova, V.; Bonartseva, G.A.; Berlin, A.A.; Bonartseva, G.A.; et al. Comparative Structure-Property Characterization of Poly(3-Hydroxybutyrate-Co-3-Hydroxyvalerate)s Films under Hydrolytic and Enzymatic Degradation: Finding a Transition Point in 3-Hydroxyvalerate Content. Polymers 2020, 12, 728. [CrossRef] [PubMed]

46. D'Amico, D.; Montes, M.I.; Manfredi, L.B.; Cyras, V.P. Fully bio-based and biodegradable polylactic acid/poly(3-hydroxybutirate) blends: Use of a common plasticizer as performance improvement strategy. Polym. Test. 2016, 49, 22-28. [CrossRef]

47. Karahaliloglu, Z.; Ercan, B.; Taylor, E.N.; Chung, S.; Denkbaş, E.B.; Webster, T.J. Antibacterial Nanostructured Polyhydroxybutyrate Membranes for Guided Bone Regeneration. J. Biomed. Nanotechnol. 2015, 11, 2253-2263. [CrossRef]

48. Jendrossek, D.; Pfeiffer, D. New insights in the formation of polyhydroxyalkanoate granules (carbonosomes) and novel functions of poly(3-hydroxybutyrate). Environ. Microbiol. 2014, 16, 2357-2373. [CrossRef] 